Portland State University

PDXScholar

Fall 11-21-2017

\title{
The Revolution Will Not Be Politicized: Political Expression in the Manga Adaptations of Kanikōsen
}

Benjamin Robert Burton

Portland State University

Follow this and additional works at: https://pdxscholar.library.pdx.edu/open_access_etds

Part of the Japanese Studies Commons

Let us know how access to this document benefits you.

\section{Recommended Citation}

Burton, Benjamin Robert, "The Revolution Will Not Be Politicized: Political Expression in the Manga Adaptations of Kanikōsen" (2017). Dissertations and Theses. Paper 4157.

https://doi.org/10.15760/etd.6045

This Thesis is brought to you for free and open access. It has been accepted for inclusion in Dissertations and Theses by an authorized administrator of PDXScholar. Please contact us if we can make this document more accessible: pdxscholar@pdx.edu. 
The Revolution Will Not Be Politicized

Political Expression in the Manga Adaptations of Kanikōsen

by

Benjamin Robert Burton

A thesis submitted in partial fulfillment of the

Requirements for the degree of

\author{
Master of Arts \\ in \\ Japanese \\ Thesis Committee: \\ Jon Holt \\ Laurence R. Kominz \\ Suwako Watanabe
}

Portland State University

2017 


\begin{abstract}
Kobayashi Takiji’s (1903-1933) Kanikōsen (The Crab Cannery Ship, 1929), the outstanding work from the proletarian literary movement, experienced an influx of new adaptations into various mediums during the years that preceded and followed the "Kanikōsen boom" of 2008. This thesis focuses on two manga adaptations that provide readers with starkly different takes on the original story. Using theories by Scott McCloud and Azuma Hiroki, I first attempt to draw parallels between the form of manga and that of the novel. Then, I examine the manner in which the most explicitly political content of the novel is adapted into the manga versions. Through this examination of form and content, it becomes apparent that, despite their differences, both adaptations reinforce a vague, individualist-humanist ideology that undermines the notions of class consciousness and class struggle that are central to the narrative of Kanikösen. This diminishing of the explicitly "Red" aspects of the original reflects the Japanese public's general aversion to politics that has persisted since the early 1970's until this day.
\end{abstract}




\section{Acknowledgements}

This thesis never would have happened without the unwavering support and sage guidance I received from Professor Jon Holt. Not to mention the incredibly rewarding opportunity to co-teach a course on manga alongside him. I am so grateful to have been able to share landmark works from the medium while practicing the application of comics theory with a wonderful class of eager students. I am confident that this experience added new depth and perspective to my analysis on the form of the manga adaptations.

I also must extend my most sincere gratitude to my thesis committee members, Professor Laurence R. Kominz and Professor Suwako Watanabe. Your feedback and suggestions helped shape my thesis into a more complete piece of writing.

To my partner, Nobuko Horikawa: your love, support, and unique insight kept me afloat throughout this entire process. I couldn't have done it without you.

Finally, a raised fist of solidarity to the international community of Takiji fans and researchers. May your passion and commitment to preserving and sharing the works of Takiji inspire new generations to join in the fight against injustice and inequality around the world. 
Table of Contents

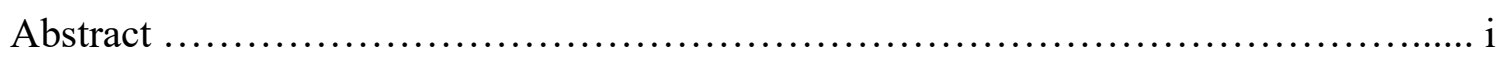

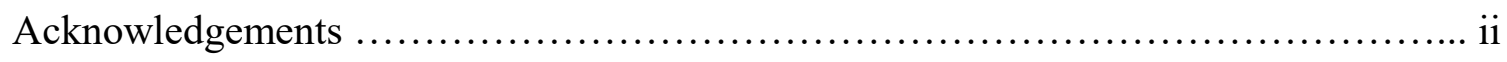

Table of Contents ............................................................................................... ii

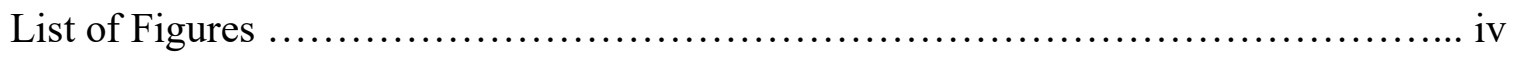

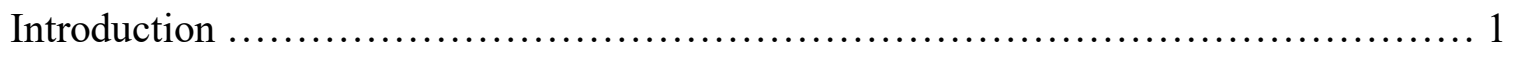

On Form

Chapter 1

From the Everyman to Shōnen Hero: Examining the Group Protagonist ................ 7

Chapter 2

Subject(s)-to-Subject: Panel Transitions and their Ideological Effects ................. 26

Chapter 3

On Content

The Path (Back) to Petit Bourgeois Realism ................................. 52

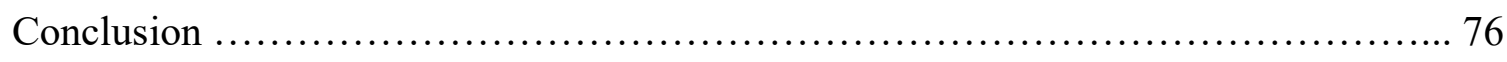

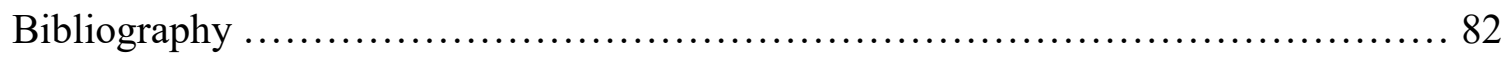




\section{List of Figures}

Figure 1. McCloud's icon can explain how we find the human "face" in everyday objects. 15.

Figure 2. The cast of the Manga de dokuha adaptation. 19.

Figure 3. Shonen manga heroes. 21.

Figure 4. The group protagonist is effectively visualized in the Takiji Library adaptation.

23.

Figure 5. Asakawa in the Takiji Library adaptation. 24.

Figure 6. McCloud's six types of closure. 27.

Figure 7. Morimoto and Akiyuki at the center of the resistance in Manga de dokuha. 31.

Figure 8. Asakawa reaching for his pistol. 32.

Figure 9. "Don't act so big." 33.

Figure 10. Morimoto in quiet reflection. 34.

Figure 11. "Aspect-to-aspect" panels exploring the tense mood on board the ship. 35.

Figure 12. The resistance is crushed. 36.

Figure 13. Morimoto's last stand. 38.

Figure 14. A two-page splash dedicated to Morimoto's punch. 38.

Figure 15. Who throws the punch? 41.

Figure 16. Collective boots, collective resistance. 43.

Figure 17. The "spinning camera" used to powerful effect. 44.

Figure 18. The delegates confront Asakawa. 46.

Figure 19. Asakawa's intimidating presence. 47.

Figure 20. The fishermen have had enough. 47.

Figure 21. The elated faces of the ship workers. 48. 
Figure 22. The delegates surrounded; the resistance quashed. 49.

Figure 23. In Dokuha, sometimes class-consciousness comes easy. 61.

Figure 24. The panel narrates, "The missing boat did not return." 62.

Figure 25. The slowdowns begin. 63 .

Figure 26. Morimoto dreams of a better life in Communist Russia. 67.

Figure 27. Left: The original photograph of Takiji's family and friends surrounding his dead body. Right: The Takiji Library's adaptation of this moment. 70.

Figure 28. A manga take on lèse-majesté. 77. 


\section{Introduction}

Much has been written on the 2008 "Kanikōsen boom" (The Crab Cannery Ship boom) centered around the 1928 breakout novel by Kobayashi Takiji (1903-1933) about the inhumane working conditions aboard an eponymous crab-canning factory ship. The novel unexpectedly became a best-seller in Japan even though nearly a century had passed since its original publication. ${ }^{1}$ Sales of the book were ten times their hitherto annual average and the surge in public interest was bolstered by new adaptations for manga, theatre, and film. ${ }^{2}$ However, Kanikōsen is no stranger to adaptations; as of this writing, six stage adaptations, two film adaptations, and five manga adaptations of the novel exist. In fact, the Tokyo Geijtusuza Troupe most recently completed a special tour of their production of Kanikōsen for an impressive 26 nights in the Chūbu and Hokuriku regions of Japan. ${ }^{3}$ Indeed, there is something about Takiji's work that continues to inspire both auteurs and larger production companies to reimagine the story for a new generation. However, creating a successful, compelling, and faithful adaptation of Kanikōsen is no easy task. Not only do the novel's politics have the potential to alienate modern audiences but even the text itself presents difficulties to those wishing to translate the story into a visual medium. In short, the 'adapters' must contend with issues

\footnotetext{
${ }^{1}$ Heather Bowen-Struyk, "Why a Boom in Proletarian Literature in Japan? The Kobayashi Takiji Memorial and The Factory Ship," The Asia-Pacific Journal Vol. 26-1-09 (2009); Norma Field, "Commercial Appetite and Human Need: The Accidental and Fated Revival of Kobayashi Takiji's Cannery Ship," The AsiaPacific Journal Vol. 8-8-09 (2009).

2 In "Commercial Appetite and Human Need," Norma Field sums up the genesis of the boom as follows: "Two liberal newspaper articles, an initial book order of 150 copies, then a conservative newspaper article turned the trickle of interest into a flood. Finding a story that sells is of course a central preoccupation of the media, with the hoped-for outcome being a cascade of sales. The aura of newsworthiness prompted publishers to reprint more copies, bookstores to provide more space, provoking further media attention, then more copies reprinted."

3 "Engeki kanshō Kai: Kanikōsen," Tokyo geijutsu za, accessed August 12, 2017, http://www.tokyogeijutsuza.co.jp/filename48.html
} 
regarding content and form when attempting to re-envision Kanikōsen. Perhaps these difficulties are one reason why the adaptations of Kanikōsen vary significantly in terms of faithfulness to the original text. In this light, a comparison of the adaptations can offer us insight into not only the exact nature of these difficulties but also tell us more about Takiji's text itself. By examining both the form and content of the adaptations, we can illuminate what aspects of Takiji's texts are being presented to new audiences and judge if these remain congruent with the author's intentions. To this end, a comprehensive review of all adaptations available would be ideal. However, the scope of such a project is beyond what I have attempted in this thesis. Instead, I have narrowed down my analysis to two manga adaptations for reasons that are detailed below.

The ubiquity of manga in Japan cannot be overstated. Go to any convenience store in Japan and you will find a steady selection of manga periodicals and tankōbon ('standalone books') lining the shelves. And, while sales of printed manga have been on the decline, the manga market in Japan is still a force to be reckoned with; its market shares occupy over a quarter of the entire Japanese publishing industry. ${ }^{4}$ Furthermore, manga's relatively low cost, ease of access, and general public appeal makes it an ideal medium for adapting a story to reach a wide, Japanese audience. With this in mind, choosing manga as the medium of choice for this project seemed like a natural choice. However, I had to take different considerations into account when deciding to focus on only two of the five manga adaptations that exist.

\footnotetext{
4 “Japan's Manga Market Grows 0.4\% in 2016, Digital Sees 27.5\% Increase," Anime News Network, last modified March 18, 2017, http://www.animenewsnetwork.cc/news/2017-03-18/japan-manga-marketgrows-0.4-percent-in-2016-digital-sees-27.5-percent-increase/.113129.
} 
My criteria for selection was judged in terms of accessibility and relevance. In terms of accessibility, I wanted to be able to gauge how many readers may have purchased or read one or some of the manga adaptations. However, I could only find concrete sales numbers on one adaptation, Kanikōsen: manga de dokuha. ${ }^{5}$ This adaptation was published by East Press in October of 2007 and enjoyed sales of some 200,000 units during the Kanikōsen boom in late 2008. ${ }^{6}$ This number is significant when considering that sales of novel jumped to approximately 500,000 copies during the same period of time. ${ }^{7}$ It is worth mentioning that the series also published an adaptation of Das Kapital in December of the same year and enjoyed moderate success as well. ${ }^{8}$ However, finding circulation numbers for the other adaptations proved difficult. Therefore, I had to consider other ways in which the manga may have reached its audience. I learned that the Takiji Library had sponsored the publication of a manga adaptation and even published it to be freely viewed online. ${ }^{9}$ It is on this point that I took relevance into account, as this adaptation was part of the larger efforts to revitalize public interest in Takiji that led to the Kanikōsen Boom. As Norma Field writes:

To be sure, during the five years preceding the boom, several developments laid the ground for expanding interest in Takiji beyond the tiny circles of devotees. A Takiji Library ... was established through the remarkable initiative of Sano Chikara, a hugely successful businessman and graduate of Takiji's alma mater,

\footnotetext{
${ }^{5}$ The Manga de dokuha (read it all in manga) series began in 2007, publishing literary classics as manga in order to reach a wider audience.

${ }^{6}$ C. B. Liddell, "Red star rising: With global capitalism on ropes, communism gains in Japan," Japan Today, last modified January 17, 2009, accessed September 6, 2016, http://www.japantoday.com/category/lifestyle/view/red-star-rising-with-global-capitalism-on-ropescommunism-gains-in-japan.

${ }^{7}$ Bowen-Struyk, "Why a Boom in Proletarian Literature in Japan?"

${ }^{8}$ The Associated Press, "'Das Kapital' comic has mass appeal," The Japan Times, last modified December 24, accessed September 6, 2016, http://www.japantimes.co.jp/news/2008/12/24/national/das-kapital-comichas-mass-appeal/

${ }^{9}$ The Takiji Library has posted the manga on this website: http://www.takijilibrary.jp/announce/2007/20070927.html
} 
Otaru University of Commerce. The Library became a centralized source of information; it also sponsored the publication of ten books including a manga version of The Cannery Ship to attract a young readership to, and together with the University, co-sponsored a series of international symposia. ${ }^{10}$

Thus, it was through this admittedly subjective process that I came to choose what will henceforth be called the Manga de dokuha and Takiji Library adaptations as the subjects of my analysis.

In the following three chapters, I analyze the manga adaptations in terms of both form and content. In a sense, this echoes the lively debates the proletarian writers and critics engaged in during the heyday of the proletarian literary movement. Takiji and his contemporaries were in a constant polemic about how to popularize the genre, what kind of writing style to employ, the distinctions or non-distinctions between political and artistic value, and other issues related to content and form during their period as active writers. ${ }^{11}$ The differing ways in which the adaptations deal with the formal group protagonist and political content of the original work reveal to us that, in a way, the debate regarding form and content is still very much alive today. Thus, I have organized my chapters under the subheadings, "On Form" and "On Content."

In "On Form," I begin with a chapter entitled "From the Everyman to Shönen Hero" that explores how the group protagonist of Kanikōsen has been adapted to manga. The group protagonist is one of the most unique formal aspects of the novel and, I find, essential to conveying Takiji's message of collective action. However, moving from the text-based group protagonist to a visual medium like manga results in a host of new

\footnotetext{
${ }^{10}$ Field, "Commercial Appetite and Human Need."

${ }^{11}$ Shea writes in-depth on this topic in his chapter, "NAPF to KOPF: Theoretical developments" in Leftwing Literature in Japan.
} 
problems that significantly affect the text. Using theories developed by Scott McCloud and Azuma Hiroki for analyzing comics and manga, respectively, I show how, despite the difficulty in adapting the group protagonist to manga, it can be done in a manner that is faithful to the original work, as exhibited by the Takiji Library adaptation. On the other hand, the Manga de dokuha adaptation's over-reliance on visual shōnen tropes produces a visual narrative that undermines the message of collective action in Kanikosen.

In chapter 2, "Subject(s)-to-Subject," I utilize Scott McCloud's theory on panel transitions to demonstrate how the adaptations either undermine or reinforce Takiji's message of collective action, using the climax as my focal point of analysis. What I find, and what comes to reveal itself to be a trend, is that the Manga de dokuha adaptation's persistent focus on the main characters of the story inadequately captures the spirit of the original text. On the other hand, the Takiji Library adaptation once again demonstrates how the form of the Kanikōsen can be faithfully, and effectively, realized in manga. In short, these two chapters demonstrate how the visual representation of characters and key scenes in the novel can significantly impact the overall message of the work. While the Takiji Library demonstrates its faithful adherence to the formal qualities of the original text through its visual style, the Manga de dokuha adaptation goes in an altogether different visual direction that results in a misleading adaptation of Takiji's work.

However, despite their visual differences, both adaptations do share similarities in terms of content. I explore this point in greater detail in chapter 3, "On Content: The Path (Back) to Petit Bourgeois Realism." I find that both adaptations root their narrative in an individualist-humanist ideology in differing ways. This can be problematic because Takiji and his contemporary, Kurahara Korehito, were trying to overcome vague notions 
of individualism and humanism in their work, as exhibited by Kurahara's conception of proletarian realism. However, it is the politics of Kanikösen that appear to be the most divisive in the adaptations. While the Manga de dokuha adaptation does incorporate some of the overtly political content found in the original work, it does so in a superficial way that does not elevate the adaptation into any meaningful discussion about classconsciousness or class struggle. Instead, its focus remains on the main character, Morimoto, and his own personal struggle with the villainous oppressor, Superintendent Asakawa. On the other hand, there is a conspicuous absence of any scenes related to Red content in the Takiji Library adaptation. This aversion to leftist politics is further exacerbated by the frame story, in which the political activism of Takiji seems to be watered down, placing emphasis instead on his tragic death instead. Both adaptations thus appear to be informed by a contemporary humanist ideology reminiscent of the petit bourgeois tendencies that Takiji and Kurahara were trying to avoid in their work.

Looking at these two manga adaptations, one is reminded of the difficulties the proletarian writers had when trying to popularize a genre of literature so closely tied to politics. On top of that was the added hurdle of communicating potentially complex ideas to a readership that was not entirely comprised of the intelligentsia. Fast forward to nearly eighty years later, where, despite having unparalleled outreach to the masses thanks to the development of new media and the internet, there still lacks a smooth intersection between leftwing politics and popular media. This is not to say that Japan is unique in this regard. However, the adaptations of Kanikōsen do offer us a glimpse into the nature of this complicated relationship between popular media and openly leftist political expression. 


\section{On Form}

\section{Chapter 1 - From the Everyman to Shōnen Hero: Examining the Group Protagonist Writing the Group Protagonist}

Some say that the circumstances behind Takiji's death are mainly why Kanikōsen is considered to be the most important work from the proletarian literary movement. On the topic of Takiji, Shea writes, "[o]ne feels, at least, that the real source of his literary acclaim among many critics is, unconsciously perhaps, his political martyrdom." ${ }^{12}$ Keene echoes these sentiments, positing that Takiji’s “distinction may owe more to his political martyrdom than literary excellence."13 In the wake of the Manchurian Incident and with increasing repression of Japanese leftists, Takiji went underground to avoid arrest while engaging in Party activities and maintaining a prolific writing output. ${ }^{14}$ Unfortunately, he could not evade the watchful eye of the special police forever. On February 20, 1933, set up by a spy who infiltrated the then-illegal Communist party, Takiji was arrested and taken to the Tsukiji Police Station for interrogation. His loyalty would spell his demise, as he refused divulge any information that could be used against his comrades or the Party. Unspeakable brutality was inflicted upon Takiji by the hands of the police. Merely hours after his arrest he was no longer of this world. Takiji's death signaled the end of the proletarian literary movement and secured his legacy as a political martyr. In a sense, this sole figure - this hero's — death heralded the demise of many players in the fight for proletarian literature to overcome imperialistic hegemonic forces. And, in the decades

\footnotetext{
${ }^{12}$ G.T. Shea, Leftwing Literature in Japan, A Brief History of the Proletarian Literary Movement (Tokyo: Hosei University Press, 1964), 275.

${ }^{13}$ Donald Keene, Dawn to the West (New York: Holt, Rinehart, and Winston, 1984), 617.

${ }^{14}$ Ibid., 621.
} 
following the war, he would be uniquely remembered as one of the few Japanese authors who died for their writing, with Kanikōsen as his shining achievement. However, solely attributing Kanikōsen's enduring reputation to Takiji's sacrifice obscures the novel's literary merits. Kanikōsen is a novel that assails all five senses, ${ }^{15}$ employs cinematic qualities to powerful effect, ${ }^{16}$ and strikingly depicts the "vivid, believable details of life aboard the ship." ${ }^{17}$ Above all, Takiji's penchant for experimentation is what elevates the work. Moreover, I argue that the group protagonist found in Kanikōsen is what stunningly exemplifies Takiji's ability to ideologically synchronize content and formthat is the true success of his novel.

The group protagonist is one of the most formally unique aspects of the novel. Readers are not given names nor physical descriptions of the cast of workers. On the other hand, the primary antagonists, Superintendent Asakawa and company agent Suda, are referred to by name. When a worker is singled out, they are either referred to by a nickname or by the position they occupy on the ship. One passage during the strike scene concisely illustrates this device.

All the factory workers were brought to where the fishermen had gathered. The stokers and sailors joined them within the hour. Everyone stood assembled on deck. The Stuttering Fisherman, the students, Shibaura, and Don't-Act-So-Big jointly drew up a list of demands. They decided to confront the manager and his cohorts with it, in everyone's presence. ${ }^{18}$

\footnotetext{
${ }^{15}$ Faliero Salis, “Kanikōsen no genzai,” in Takiji no bungaku, sekai e: 2012 Otaru Kobayashi Takiji kokusai shinpojiumu hōkoku shū, ed. Ogino Fujio (Otaru: Otaru Shōka Daigaku Shuppan Kai, 2013 ), 41. ${ }^{16}$ Shimamura Teru, "Commentary” in 30 pun de yomeru ... daigakusei no tame no manga Kanikōsen (Tokyo: Higashi Ginza Shuppan sha, 2006), 171.

${ }^{17}$ Dawn to the West, 619.

18 Takiji Kobayashi, The Crab-Cannery Ship and Other Novels of Struggle, trans. Željko Cipriš, (Honolulu: University of Hawai'i Press, 2013), 89. All subsequent translations of the novel are Cipris' unless otherwise stated and in the latter case, they are my translations.
} 
Here we see the variety of groups aboard the ship - factory workers, fishermen, stokers, sailors, and students — along with the few characters given nicknames by the narrator. ${ }^{19}$ By using the group protagonist, Takiji can depict the ship workers as a single, united entity of resistance. It also highlights the conflict between the many unnamed workers against the few named agents of the company.

Takiji elaborates on the significance of this device in a letter he sent to Kurahara Korehito, the "leading Marxist theoretician during the heyday of the Japanese proletarian art movement." ${ }^{20}$ In the letter, Takiji writes that the group protagonist was an improvement on his debut piece, March 15, 1928 (Sen kyū hyaku ni jü hachi nen san gatsu jü go nichi, 1928), in which he attempted to depict the interiority of each character in great detail. While Takiji was not the first writer to attempt to depict the group as a main character, he believed Kanikōsen was the first time it had been done on such a scale. ${ }^{21}$ Furthermore, Takiji had hoped that "proletarian literature would advance upon the trail he had blazed." 22 Many proletarian critics at the time praised this attempt in Takiji's novel. However, for Kurahara, this experiment brought up the question as to whether or not it was necessary to bury the individual in proletarian literature. Kurahara posited that " $[\mathrm{t}]$ he materialistic view of history has never denied the role of the individual in society or history. What it has denied is the view of the bourgeois 'super-man', the

\footnotetext{
${ }^{19}$ The nicknamed characters are established by the narrator at varying points in the text. The nicknames are created through different ways. They can represent a specific trait the characters possess, as in the case of the Stuttering Fisherman (domori, lit. 'to stutter'); where one comes from (Shibaura); or something they said that the other fishermen took a liking to, as in the case of Don't-Act-So-Big (威張んな, lit., 'don’t act haughty').

${ }^{20}$ Mats Karlsson, "Kurahara Korehito's Road to Proletarian Realism," Japan Review no. 20 (2008): 231. http://www.jstor.org/stable/25791325.

${ }^{21}$ Maedakō Hiroichirō's "Third-Class Passengers" (1920) also employed a similar device.

${ }^{22}$ Dawn to the West, 618.
} 
individual opposing society." 23 The problem was primarily about establishing the individual within the group, and describing "the character and psychology of the individuals as representatives of various classes." ${ }^{24}$ Kurahara's critique aside, writing the group as the main character is one reason why the novel remains as the representative work from the Japanese proletarian literary movement. As Shea writes, "the attempt itself marks it as an epochal work in Japan's proletarian literary movement, and the measure of success it achieved has generally earned it the acclaim of being the best representative work of Japanese proletarian literature." ${ }^{25}$ Furthermore, this device serves to reaffirm the novel's thesis: that the proletariat will achieve victory only through truly collective action. Nowhere else is this more apparent than in the climax.

In the climax, the ship workers come to realize that their lives are at stake should they continue to adhere to Asakawa's brutal and unrelenting demands. This realization comes in the wake of the death of a fellow worker, Yamada, ${ }^{26}$ who came down with a case of beri-beri and was denied adequate medical treatment. This, along with other developments throughout the story, cause the workers to organize, choose representatives, and eventually strike. The men stop working, gather en masse, draft up a list of demands, and present them to Asakawa. In response, Asakawa smugly retorts, “Listen up. Here's what I'll do. I'll give you my gracious response before tomorrow

${ }^{23}$ Leftwing Lit., 322.

${ }^{24}$ Ibid., 322

${ }^{25}$ Ibid., 322.

${ }^{26}$ This is one instance in the novel where a ship worker is given a name. However, in this case it is only after he has died. Another worker, Miyaguchi, is given a name when he hides from work on the ship. Once caught, he is thrown into the bathroom for several days and is described as "barely alive" with lips the "dead color of blue ink" (The Crab Cannery Ship, 38). 
morning." 27 The workers take exception to Asakawa's tone, resulting in a fracas that closes the scene.

When morning comes, the men are excited to see ships headed their way from the Naval destroyer that was tailing the cannery-ship for both protection and surveying purposes. Most of the men are elated, thinking the Navy is on their side and will help resolve the strike in their favor. They could not have been more wrong. The soldiers board the ship, rifles drawn with bayonets attached, and swiftly surround the representatives of the strike.

They were not allowed to say anything. Denounced as "thugs," "subversives," and "Red traitors," the nine delegates were escorted to the destroyer at the point of bayonets. It all happened with lightning speed as the others watched in a daze, uncomprehending. Not a word of objection was allowed. They saw their efforts go up in flames as absurdly as a blazing sheet of paper. Their revolt had been disposed of with the greatest ease. ${ }^{28}$

The strike is a total failure. Crestfallen, the men return to work with an emboldened Asakawa forcing even harsher demands on them than before. However, they come to realize the reason behind their defeat: the choice of electing a few exceptional individuals to represent them, rather than banding together as a collective whole. Having all 300 hundred workers aboard the ship together, they strike again, this time in success.

Despite Kurahara's critique of the group protagonist, the conclusion of the novel does reaffirm his statement about the bourgeois super-man; while a strike may fail when it is left to an exceptional few (super-men), it will succeed when it is comprised of a singular, united group of workers. This is the essence of Takiji's theory of collective

${ }^{27}$ The Crab Cannery Ship, 92.

${ }^{28}$ Ibid., 94. 
action. And writing the group protagonist serves to bolster this point at the level of the text. Kanikōsen's message of collective action is thus manifested through a clever fusion of form and content. If Takiji opted for a more traditional approach to the novel's protagonists, would Kanikōsen have garnered the reputation it enjoys today? It is doubtful. However, what happens to this textual device when it is adapted into a visual medium, like manga? The Manga de Dokuha and Takiji Library adaptations offer two different takes on the group protagonist found in Kanikōsen.

\section{Adapting the Group Protagonist}

As mentioned earlier, Kanikōsen has enjoyed numerous adaptations into mediums such as theatre, film, and manga. However, all these mediums share a fundamental component that is absent in the novel: the primacy of the visual. While Takiji could write a cast of over 300 laborers without naming them or depicting their physical traits in detail, this is simply not feasible in visual adaptations that try to preserve the realist narrative of Kanikōsen. Komori Yōichi maintains, "when adapting to manga, one must draw the individual faces and bodies of each character." ${ }^{29}$ Not an unreasonable observation. However, he goes on further to suggest that Kurahara's reservations about burying the individual are resolved due to the medium. But is this really the case? In the language of manga, or, better yet, the vocabulary of comics, meaning is as visual as it is textual. Choices regarding character designs, style, and levels of photographic realism all play a significant role in the creation of meaning. Thus, in the case of Kanikösen, the way

${ }^{29}$ Komori Yōichi, "Kaisetsu" in Kanikōsen, vol. 4 (Tōkyō: Shinchōsha, 2009), 3. 
in which adaptations visually represent the cast of laborers can significantly affect the overall impact of the work.

The Manga de dokuha and Takiji Library adaptations occupy two ends of the spectrum regarding how they depict the group protagonist. At one end, the Manga de dokuha adaptation eschews any effort to preserve this aspect of the original text; at the other end, the Takiji Library adaptation exhibits a clear effort to retain the group protagonist at the visual level. These contrasting approaches result in drastically different narratives. Drawing from theories of comics and otaku culture developed by Scott McCloud and Hiroki Azuma, respectfully, I will show how the Manga de dokuha adaptation is informed by a shōnen manga (boys' comics) database for its character designs, resulting in a visual style that does not accurately capture the spirit of Kanikosen. Conversely, I find that the Takiji Library's visual approach is congruent with Takiji's message and faithfully recreates the atmosphere of the text through its balanced, iconic visual style.

\section{A Database of Icons}

In McCloud's seminal work, Understanding Comics, he introduces the concept of the icon to explain how cartoons can produce meaning and affect reader identification through varying degrees of photorealism. He defines the icon as "any image used to represent a person, place, thing, or idea." ${ }^{30}$ According to McCloud, levels of iconic content vary depending on how closely they resemble the real-world subject. Thus, in the

\footnotetext{
${ }^{30}$ Scott McCloud, Understanding Comics: The Invisible Art (Northampton: Tundra Publishing, 1993), 27.
} 
case of pictorial icons - the stuff of comics — meaning becomes fluid as a result. For comics, then, the creation of meaning is perhaps even more visual than textual. McCloud calls this process "amplification through simplification." He writes:

When we abstract an image through cartooning, we're not so much eliminating details as focusing on specific details. By stripping down an image to its essential "meaning," an artist can amplify meaning in a way that realistic art can't. ${ }^{31}$

With the details stripped away, an icon can magnify potential associations with an image. McCloud uses the image of an electrical outlet, explaining how just three lines leaves the impression of a human face; or how three circles can conjure up the image of Mickey Mouse (fig. 1). However, simplification also influences reader identification. McCloud argues that readers are less likely to identify with a photorealistic image, maintaining that "when you look at a photo or realistic drawing of a face, you see it as the face of another. But when you enter the world of the cartoon, you see yourself." Thus, "the cartoon is a vacuum into which our identity an awareness are pulled, an empty shell that we inhabit which enables us to travel in another realm. We don't just observe the cartoon, we become it!" ${ }^{32}$ In short, the degrees of photorealism and iconic content both produce meaning but also create a space in which the reader can insert them self within a character or cartoon world.

\footnotetext{
${ }^{31}$ Ibid., 30.
}

32 Ibid., 36. 

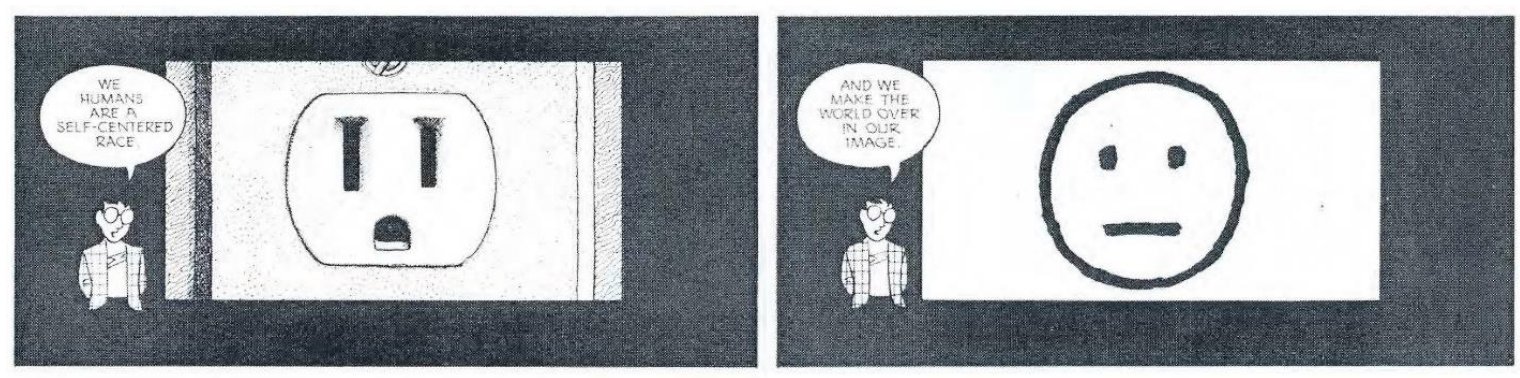

Figure 1. McCloud's icon can explain how we find the human "face" in everyday objects.

However, what is absent in McCloud's theory is the sociocultural context in which cartoons emerge and how that affects the creation of meaning. This is an important aspect to consider, as he defines the icon as an image that can represent ideas. The cartoon is thus never an empty space. For instance, to find Mickey Mouse in three circles requires that one already possesses an awareness of the ubiquitous — or iconic — character. It may be better to say that, through images and text, cartoons can guide readers towards a set of meanings and create certain expectations within a specific cultural framework. However, where do these ideas come from? Hiroki Azuma's theory of the database model can explain the conceptual space where these ideas - or icons - are stored.

Azuma developed the database model to explain the proliferation of derivative works and declining of interest in grand narratives in otaku culture. He found that the otaku are no longer primarily interested in overarching narratives in the media they consume. Now, otaku are "focused exclusively on the settings and character designs as objects for excessive interpretation." ${ }^{33}$ In other words, otaku are primarily concerned discernible pieces - characters, settings, tropes — of the work, rather than the message or the world the work may be attempting to present. These categorizable traits are what

\footnotetext{
${ }^{33}$ Hiroki Azuma, Otaku: Japan's Database Animals, trans. Jonathan E. Abel and Shion Kono (Minneapolis: University of Minnesota Press, 2009), 37.
} 
make up the database model. Azuma focuses on the otaku's obsession with moe, or alluring elements, to explain this trend. He uses Di Gi Charat, a character who was “originally created as a mascot for a dealer of anime- and gaming-related products." 34 Despite having no narrative existing behind Di Gi Charat, the character gained popularity and spanned out into a multimedia franchise. Azuma writes:

What is noteworthy in this process is that the stories and settings that form [Di Gi Charat's] world were created collectively and anonymously as a response to the market, after the character design of [Di Gi Charat] alone gained support. ${ }^{35}$

An entire fictional world with its own unique narratives sprung forth simply from a character design. Azuma carefully notes that "this development was not managed by a particular author or production company ... [t]he entire project was driven by the power of fragments; projects such as the anime or the novel, formerly discussed independently as a "work," are merely related products ... The narrative is only a surplus item, added to the settings and illustrations (the nonnarrative)." ${ }^{36}$ The pieces of Di Chi Charat's visual design thus lead to an entire fictional world that the fans could enjoy and consume. He then addresses the visual elements of Di Gi Charat. He writes how the character design is not "particularly original or attractive" and "is a result of sampling and combining popular elements from recent otaku culture." He elaborates:

I will not describe the characteristics of each element here, but note that each element, with its own origins and background, constitutes a category that has been developed in order to stimulate the interest of the consumers. It is not a simple fetish object, but a sign that emerged through market principles. ${ }^{37}$

\footnotetext{
${ }^{34}$ Ibid., 39.

${ }^{35}$ Ibid., 40.

${ }^{36}$ Ibid., 40-41.

${ }^{37}$ Ibid., 42.
} 
The case of Di Gi Charat shows how discrete visual elements can not only conjure up particular associations with certain personality traits but are also categorized within a database that can be accessed by those who are familiar with anime and manga conventions. And the database continues to grow, as Azuma writes:

As soon as characters are created, they are broken up into elements, categorized, and registered to a database. If there is no appropriate classification, a new element or category simply will be added. In this sense, the originality of an "original" character can only exist as a simulacrum. ${ }^{38}$

Thus, characters and settings can be connected across entirely different works through the traits they share or the works they may have been derived from. In other words, the character design is what tells the story for contemporary otaku/manga readers. Furthermore, parallels can be drawn between entirely separate works through discrete these visual elements, further reifying specific expectations for manga audiences.

Returning to McCloud, we can now say that the icon is the "information" that fills the database. Icons are pictorial abstractions of ideas; they are loaded with meaning and associations. They can thus be manipulated to conjure up specific ideas precisely due to the existence of a database. In the case of Di Gi Charat, her "hair sticking up like antennae," "cat ears," "maid uniform," and other specific traits make her into a moe character. That being said, one would be hard-pressed to find any moe elements in the original Kanikōsen. A faithful adaptation must draw upon a different database for its narrative. However, since the narrative does not provide readers much in the way of physical details, those adapting the novel must rely on abstract notions of what "kind" of

\footnotetext{
${ }^{38}$ Ibid., 47.
} 
people are being depicted in the text. They would need to utilize iconic content that is closely associated with the ideas of the text. However, this does not always happen in practice. Below, I will show what kind of characters populate the world of Kanikosen. Then, I will explain how the Manga de dokuha adaptation taps into the shonen manga (manga for boys) database for its character designs.

\section{From Group Protagonist to Shōnen Hero}

Kanikōsen does not feature a cast of heroes; Takiji makes no attempt to idolize the subjects of his novel. As Keene writes:

The fishermen and factory workers are by no means the clear-eyed heroes of the posters of socialist realism. Most of them are coarse, badly educated men who can endure life aboard the ship only because they were early accustomed to similarly brutal experiences. Their sexual cravings sometimes find an outlet in the young factory hands, who become their unwilling victims. The older fishermen are even ready to betray their shipmates to Asakawa in return for the reward of cigarettes, and are thoroughly indoctrinated in the old, "feudalistic" attitudes. Even among the younger men there is no leader ... to guide the others in a course of action. Kobayashi deliberately avoided creating a worker-hero who would be the counterpart to the capitalist villain Asakawa. ${ }^{39}$

Poorly educated, at times disloyal, and beholden to their physical cravings; these men are the group protagonist of Kanikōsen. Indeed, they are meant to be a realistic representation of those who grew up in the lower-strata of society, forced to eke out a living by any means possible. None possess any unique traits that make them appear superior or inferior in regard to their fellow workers. The fishermen, sailors, stokers, factory workers, and students are the everyman. Thus, an accurate visual representation of this

\footnotetext{
${ }^{39}$ Dawn to the West, 619-620.
} 
type of character should hone in on these traits. However, the Manga de dokuha adaptation takes many liberties with this aspect of the story.

The Manga de dokuha adaptation completely does away with the group protagonist. The adaptation not only provides a cast of named characters but even begins the story with a splash page dedicated to introducing the cast (fig. 2). Protagonists and antagonists are separated cleanly by the page break. On the side of the protagonists is the main character, Morimoto, a young man who joined the ship in order to save money for his impoverished family. Other characters introduced are his sidekick, a college dropout named Akiyuki, a kind-hearted, experienced laborer Miyaguchi, and the stoic Captain of the ship.

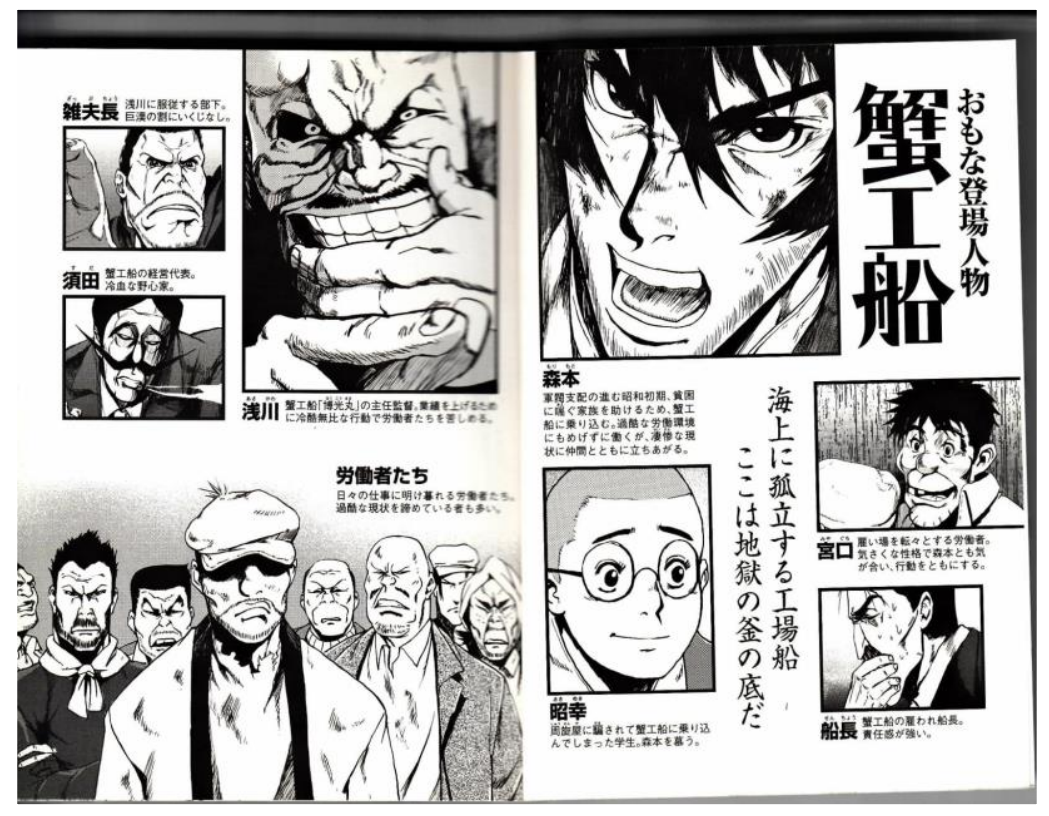

Figure 2. The cast of the Manga de dokuha adaptation.

On the opposite page readers will find the cast of villains. There is Asakawa, the brutal superintendent of the ship; the foreman, Asakawa's enormous yet cowardly underling; and Suda, a cold, calculating representative from the company. Interestingly the laborers 
are introduced on this page as well. They are drawn as rough cast of snarling thugs, creating a direct contrast with the story's protagonists on the opposite page. A split is thus formed between the nameless laborers and the few exceptional individuals in the manga.

This split is exacerbated by the visual design of Morimoto. He is drawn with spiky hair that droops perfectly over the eyes, sharp facial features, and sports an unkempt-yet-fashionable style. These traits are all iconic of the ubiquitous heroprotagonist found in countless shōnen manga. The fictional bio also tells us more about his character:

\section{軍閥支配の進む昭和初期、貧困に喘ぐ家族を助けるため、蟹工船に乗り込 む。過酷な労働環境にもめげずに働くが、凄惨な現状に仲間とともに立ち あがる。 \\ In the early days of Showa, with military control on the rise, he boarded the crab cannery-ship to save his impoverished family. He works despite the brutal labor conditions, but will stand up alongside his comrades to confront grim reality. ${ }^{40}$}

Morimoto is described in ideal terms: he is filial, hardworking, and loyal to his comrades. More than likely he was crafted to resonate with a young, male Japanese readership; readers that, when they see Morimoto for the first time, will immediately feel a sense of familiarity and have particular expectations for how he will function in the manga.

${ }^{40}$ Kanikoosen: manga de dokuha, (Tokyo: East Press, 2008), 2. 

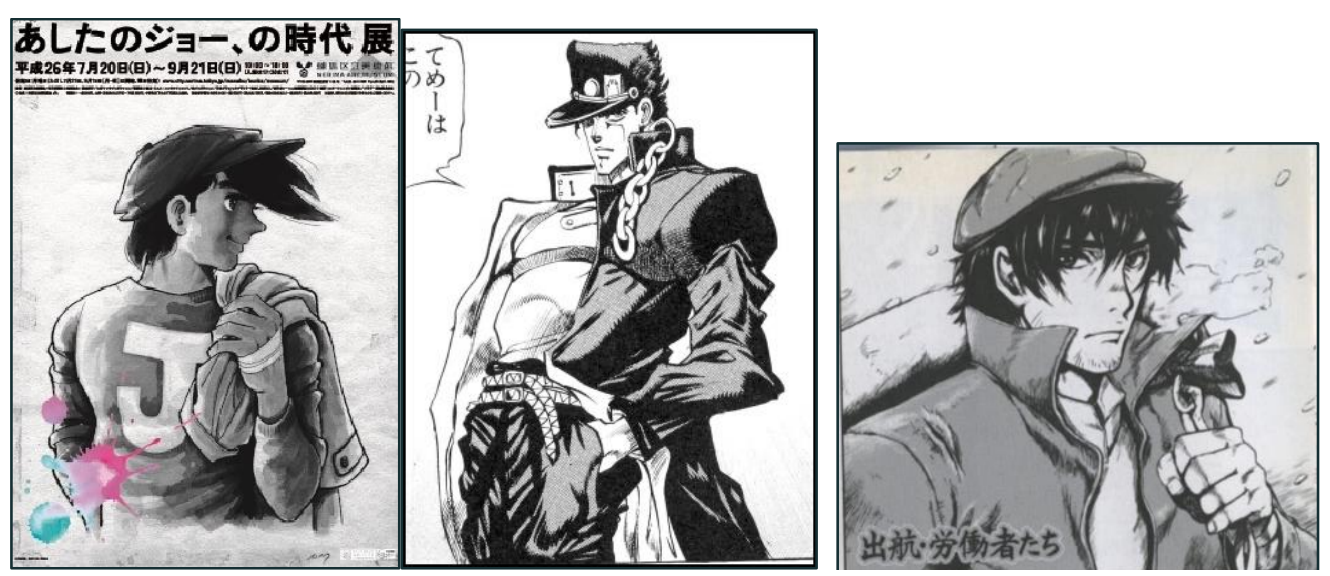

Figure 3. (Left) Yabuki Joe, the protagonist of Ashita no Joe, (center) Kūjō Jōtarō, protagonist of JoJo's Bizarre Adventure: Stardust Crusaders, (right) Morimoto from Dokuha.

This is because Morimoto's character design closely resembles that of other

iconic shōnen protagonists. While numerous similar characters may exist across a number of works, I will limit the scope of my analysis to two: Yabuki Joe from Ashita no Joe (1967-1973) and Kūjō Jōtarō of JoJo’s Bizarre Adventure: Stardust Crusaders (19891992). These two series remain incredibly popular today and continue to be adapted into new live-action films, video games, and other media. As exhibited in figure 3 , the visual resemblance is uncanny. The hat, hair, and faces are all very similar. Furthermore, Yabuki Joe often sports a coat with the collars flipped up just like the other two characters. Even the descriptions of their character traits bear many similarities. For example, Yabuki Joe is described as:

不遇な生い立ちからか孤独な不良少年だったが、後に人間的にも成長をみ せた。女心に鈍感で細やかな人付き合いは苦手だが、本質的には義理堅く 弱者に優しい人柄である。

His troubled upbringing made him into a loner-delinquent, but he shows maturity over time. He's not very sensitive to women's feelings and doesn't get along well with overly attentive people but at his heart he is fiercely loyal and shows kindness to those weaker than himself. ${ }^{41}$

\footnotetext{
${ }^{41}$ From the Wikipedia page dedicated to the characters of Ashita no Joe: https://ja.wikipedia.org/wiki/あし たのジョーの登場人物. My translation.
} 
As for Kūjō Jōtarō, he is said to be "always quiet, calm, and collected. But at his core is an explosive personality with a strong sense of justice." 42 Furthermore, much of the plot of Stardust Crusaders is concerned with saving Jōtarō's mother, who has fallen ill due to a supernatural disease and the only way to cure her is to defeat his family's intergenerational arch nemesis, Dio. At any rate, Yabuki Joe and Kūjō Jōtarō, and Morimoto exhibit loyalty, strength, and a sense of justice. Looking at these shared traits (or moe), one can see how discrete elements are recycled over time to establish specific character types. Azuma explains this phenomenon using the example of Ayanami Rei and the changing landscape of moe in the 1990's:

The emergence of Ayanami Rei did not influence many authors so much as change the rules of the moe-elements sustaining otaku culture. As a result, even those authors who were not deliberately thinking of Evangelion unconsciously began to produce characters closely resembling Rei, using newly registered moe elements (quiet personality, blue hair, white skin, mysterious power) ... Beyond Rei, characters emerging in otaku works were not unique to individual works but were immediately broken into moe-elements and recorded by consumers, and then the elements reemerged later as material for creating new characters. ${ }^{43}$

Much in the way that moe elements were repurposed to create new characters, Morimoto is an amalgamation of specific shonen hero elements that were recorded into the database. With this in mind, it is apparent that Morimoto was designed to appeal to the shōnen demographic. However, this adherence to iconic shönen character settings creates problems for an adaptation of Kanikōsen.

\footnotetext{
${ }^{42}$ From the Wikipedia page dedicated to Kūjō Jōtarō: https://ja.wikipedia.org/wiki/空条承太郎. My translation.

${ }^{43}$ Otaku, 51-52.
} 
As explained earlier, the group protagonist should represent the everyman.

However, with Morimoto standing out in both design and character, he becomes exactly what Takiji was trying to avoid. To borrow Keene's words again, Morimoto is precisely the "worker-hero" playing "counterpart to the capitalist villain Asakawa." Furthermore, the reliance on shonen tropes alienates a massive segment of the population who either do not identify with or do not enjoy comics written for young boys. While there may be difficulties in adapting the group protagonist to manga, the shonen worker-hero is not an appropriate response to this challenge. It not only represents a swift departure from one of the unique formal aspects of Takiji's work but also undermines its message of collective action.

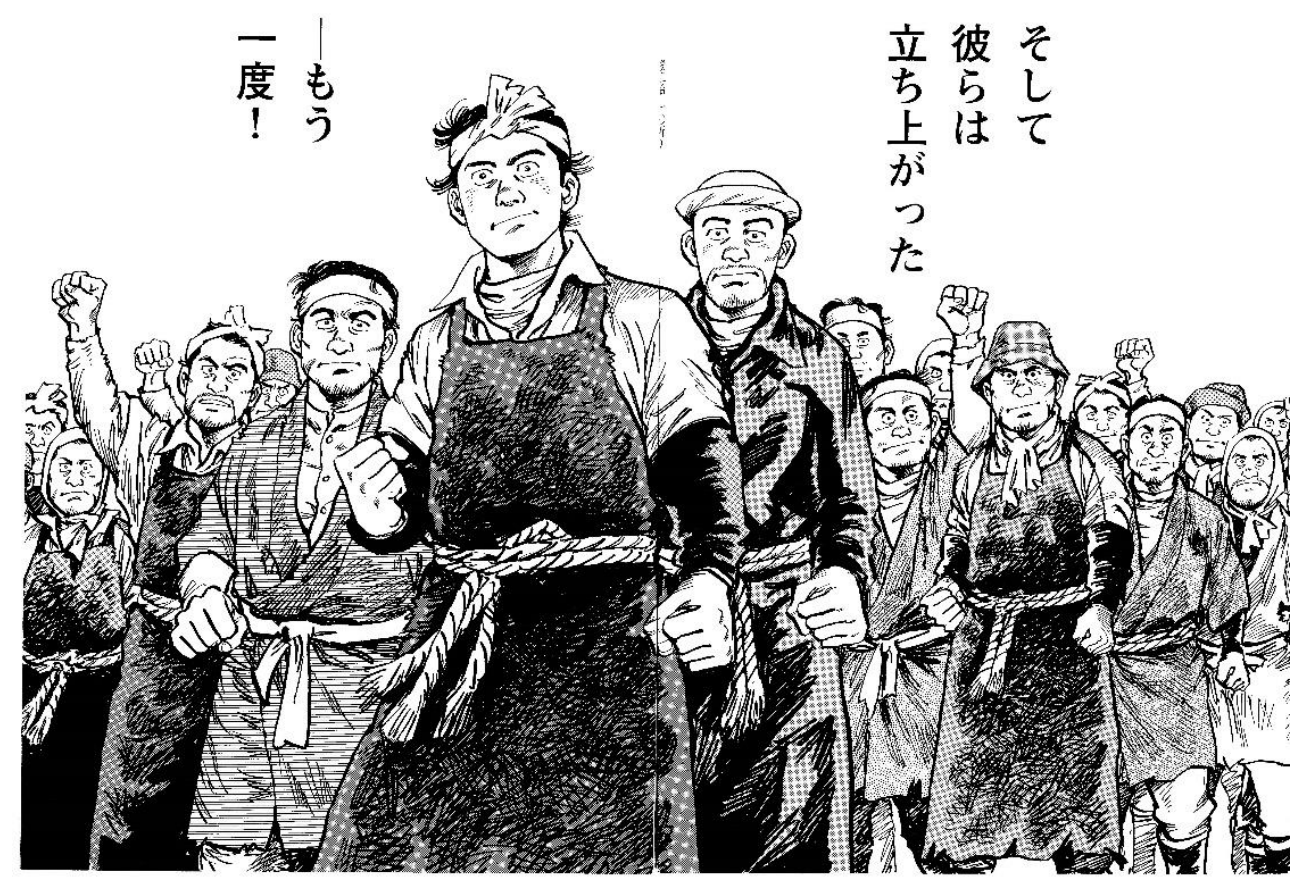

Figure 4. The group protagonist is effectively visualized in the Takiji Library adaptation. 
The Takiji Library adaptation shows one way how the group protagonist can be faithfully adapted to manga. This is demonstrated by the balanced incorporation of iconic

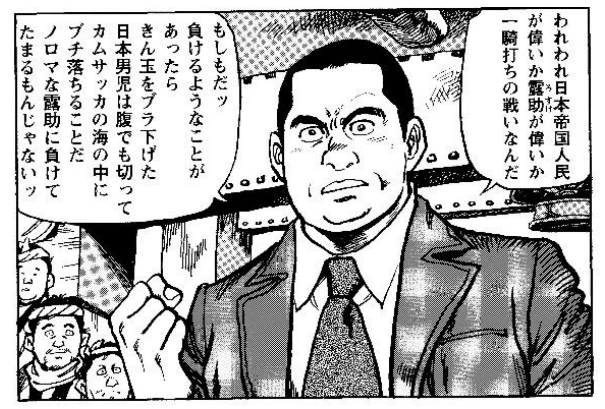

Figure 5. Asakawa in the Takiji Library adaptation. and realistic content among all characters found in the work. Looking at the cast of laborers (fig. 4), no single individual appears to stand out in significant contrast to another. Even the design of Asakawa (fig. 5) does not differ significantly from the laborers. Furthermore, while the characters are all fairly uniform in their design, a sense of individuality—humanity, perhaps—can be found in the slight differences in their clothing and facial features. In this regard, the Takiji Library adaptation faithfully depicts the group-protagonist without necessarily "burying the individual"; a design choice that critics like Kurahara surely would have welcomed. Indeed, the character design gives readers a sense that this fictional world is populated by the everyman. Unlike Manga de dokuha, there are no particular visual motifs that signify specific genre conventions. If anything, the character designs are deliberately on the iconic end of McCloud's spectrum, thus creating a greater space for reader identification without compromising to a culturally-limited, moe-hungry subset of manga otaku. Keeping the database model in mind, the most significant difference between the Manga de dokuha and Takiji Library adaptations may lie in how easy it is to trace the genealogy of their respective character designs. While Morimoto is undoubtedly shōnen, it is difficult to pinpoint any specific database the Takiji Library is tapping into with its character designs. This creates the potential for a diverse readership to engage with the narrative while remaining consistent with the central message of the original work. The 
Takiji Library adaptation shows how Takiji's textual experimentation can be faithfully recreated in manga.

Takiji's theory of collective action - the necessity of the proletariat to band together as a united whole - is embodied in both the content and form of Kanikōsen. In terms of content, it is the way in which the narrative develops to demonstrate this point. However, by writing the group as the main character, Takiji creates a text that is also formally involved in this message. Thus, form and content must work in sync for an adaptation of Kanikōsen to successfully recreate the central message of the work. However, this aspect of the original work has been adapted in different ways to varying levels of success. The Manga de dokuha adaptation is an exercise in how not to visually depict the group protagonist. With a main character that embodies many stereotypical shōnen protagonist traits, it wanders astray from the essential message of Kanikösen. On the other hand, the Takiji Library remains on the right path with its iconic and balanced visual depiction of not only the group protagonist, but all human characters in the narrative. These two adaptations shed light on the difficulties of creating a faithful adaptation of Kanikōsen in terms of its form. 


\section{On Form}

\section{Chapter 2 - Subject(s)-to-Subject:}

\section{Panel Transitions and their Ideological Effects}

The finale of the original Kanikōsen begins with a worker's uprising aboard the ship, its quick suppression by the Imperial Navy, and concludes with an epilogue informing readers of a second, successful strike resulting in the firing of Asakawa. The epilogue also points out that similar strikes occurred on other crab-canning ships, indicating that what happened aboard the Hakkō-maru was not an isolated incident.

While the strike depicted in both adaptations generally follows the same course of events as written in the original work, they differ in several ways. For instance, the Takiji Library adaptation devotes a majority of its panels to a meeting of workers on the main deck, ${ }^{44}$ whereas the Manga de dokuha adaptations places more attention on the conflict that arises when the Navy boards the ship. ${ }^{45}$ Notably, both adaptations add scenes of physical violence that are not present in the original work, but even these additional scenes differ in ways that, upon closer examination, can illuminate the ideology that informs these two works. Again, we return to McCloud, this time moving from the vocabulary of comics to its grammar to show how these two adaptations may alter, reinforce, or add something new to Takiji's seminal work.

In "Blood in the Gutter", the third chapter of Understanding Comics (UC),

McCloud introduces the concept of closure to discuss panel transitions. He writes:

Comic panels fracture both time and space, offering a jagged, staccato rhythm of unconnected moments. But closure allows us to connect these moments and

${ }^{44}$ Takiji Library, 136-140.

${ }^{45}$ Dokuha, 161-176. 
mentally construct a continuous, unified reality. If visual iconography is the vocabulary of comics, closure is its grammar. And since our definition of comics hinges on the arrangement of elements then, in a very real sense, comics is closure. $^{46}$

As comics are comprised of a series of panels

capturing fragmented moments of a visual narrative,

readers must essentially close the gap between panels - the "gutters"- in order to make sense of the time and space depicted in the succession of images and text. This is what McCloud means by closure. For example, a reader of comics may see three successive panels of the same eyethe first with the eye open, the second with the eye closed, and the third with the eye open again - and understand it as a blinking eye without much interpretive effort. On the other hand, a different comic may present one panel with a close-up of an eye followed by a panel of a cold cityscape with onomatopoeic text of the howling wind. When done correctly, readers should be able to contextualize the

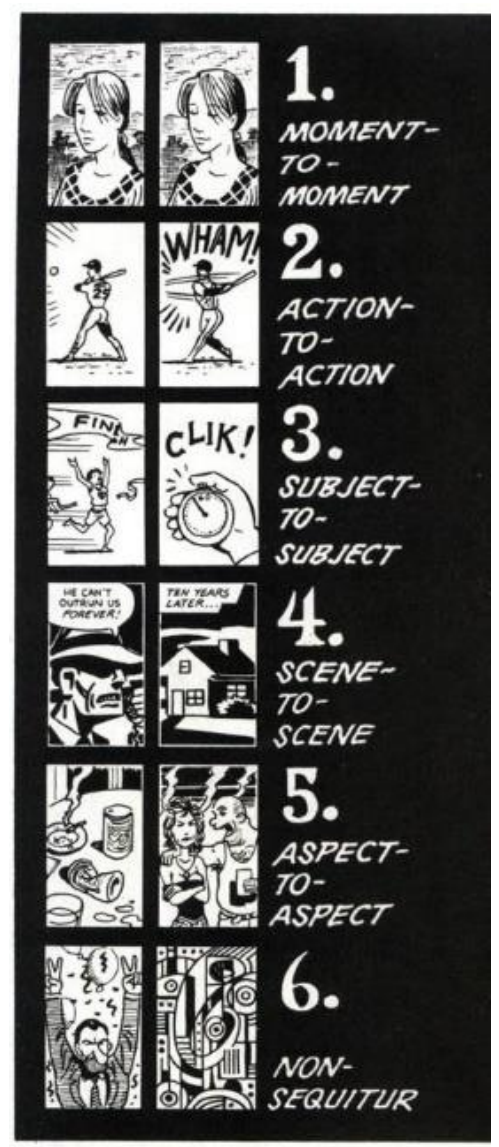

Figure 6. McCloud's six types of closure.

transition between these panels with the comic's overall narrative. McCloud calls this

"the phenomenon of observing the parts but seeing the whole." ${ }^{47}$ However, these examples only give us insight into two types of panel transitions. McCloud proposes six types of transitions found in comics, each requiring a different kind of interpretive effort

\footnotetext{
${ }^{46} U C, 67$.

${ }^{47}$ Ibid., 63.
} 
from the reader (fig. 6). Furthermore, Western comics and Japanese manga differ in how frequently they utilize certain types of closure.

The example of the blinking eye is exemplary of what McCloud defines as a "moment-to-moment" transition. According to McCloud, this type of panel transition "requires very little closure" on the part of the reader and, as its title indicates, the primary function of a "moment-to-moment" transition is to explicitly, and perhaps tediously, express the linear movement of time. ${ }^{48}$ The next type, "action-to-action" transitions, is used to depict a single subject in progression of some action. McCloud uses the example of two panels of a baseball player up to bat: the first depicting the player ready to swing with the ball in view, and the second with the player having finished their swing, complete with action lines and an emphatic "Wham!" indicating the ball has been hit. ${ }^{49}$ However, when looking at these two examples, it becomes clear that a certain amount subjectivity is involved when analyzing panel transitions. Indeed, one could argue that the "moment-to-moment" of a blinking eye is, in fact, an "action-to-action" transition as both types of transitions perform a similar function: depicting events as they are expected to happen in real life. However, "moment-to-moment" transitions place emphasis on time, whereas "action-to-action" transitions are more concerned with depicting a series of actions that will constitute an event. Nevertheless, both types of closure function as a linear expression of space and time in comics.

"Subject-to-subject" transitions are also linear, but stay "within a scene or idea" and are often used for dialogue among multiple characters or when changing the focus

\footnotetext{
${ }^{48}$ Ibid., 70.

${ }^{49}$ Ibid., 70.
} 
from one subject to another. ${ }^{50}$ In "scene-to-scene" transitions, time and space remain linear but exist across a wider scale. For instance, a panel may show a young person in Paris followed by a panel indicating that decades have passed and the person is now an adult living in some other location.

McCloud finds that much of the Western comic tradition mainly utilizes three types of closure: "action-to-action", "subject-to-subject”, and "scene-to-scene”, with "action-to-action" being the most prevalent. He reasons that their predominance comes from the notion of stories as a "series of connected events" and that these types of transitions "show things happening in concise, efficient ways." ${ }^{51}$ In other words, mainstream Western comics are primarily concerned with showing readers "what happens next" in a manner that does not require significant interpretive effort.

However, what makes Japanese manga unique is the prevalence of a fifth type of transition, "aspect-to-aspect". McCloud writes:

Aspect to aspect transitions have been an integral part of Japanese mainstream comics almost from the very beginning. Most often used to establish a mood of a sense of place, time seems to stand still in these quiet, contemplative combinations. Even sequence, while still an issue, seems far less important here than in other transitions. Rather than acting as a bridge between separate moments, the readers here must assemble a single moment using scattered fragments. ${ }^{52}$

"Aspect-to-aspect" transitions thus differ from the previously discussed transitions in that they are nonlinear and place focus on establishing or amplifying a particular mood or atmosphere rather than moving the events of the plot forward. In other words, "aspect-to-

\footnotetext{
${ }^{50}$ Ibid., 71.

51 Ibid., 76.

52 Ibid., 79. My italics.
} 
aspect" transitions are wholly affective in terms of their effect on a comic narrative.

Finally, McCloud proposes a sixth type of transition, the "non-sequitur", which "offers no logical relationship between the panels whatsoever." ${ }^{53}$ However, this type of transition is rarely found in both Western and Japanese comics, and is entirely absent from the Kanikōsen adaptations that I will discuss.

Analyzing the different types of closure can offer readers insight into the intentions behind a manga. While "action-to-action", "scene-to-scene", and "subject-tosubject" transitions primarily serve to move the plot forward, "aspect-to-aspect" transitions have the potential to illuminate what kind of emotions the comic writer is attempting to elicit from the reader. This is precisely due to the affective quality of this type of closure. With that in mind, an examination of how "aspect-to-aspect" transitions are utilized in the Manga de dokuha and Takiji Library adaptations of Kanikōsen may tell us more about the ideology that informs both of these works and show whether or not their visual language is congruent with the intentions Takiji had for his novel. We will also be able to gain a greater understanding of how these adaptations differ at a formal level.

\section{Manga de dokuha}

In this adaptation, the death of Yamada, a fellow worker, due to a case of beriberi serves as the final straw for the ship workers, especially as it is made clear that he had a high chance of survival were Asakawa to allow him to receive adequate medical

${ }^{53}$ Ibid., 72. 
attention. When Yamada's body is tossed into the cold sea during a meager funeral service, Akiyuki envisions himself as Yamada sinking quietly to the bottom of the ocean and comes to the realization that he or anyone else aboard the ship are in danger of experiencing the same fate. In response to the situation, Morimoto quietly reflects on the conversation he had with a Chinese man while in Russia. A particular idiom comes to his mind, “sei ka ryō gen” (星火燎原 ‘a single spark can start a great blaze'), and inspires him to rouse up his comrades with a fiery call to arms: "Now's the time to stand up. If you want to live, then come with me!" 54 This scene is followed by a splash page depicting the men's fists raised high in solidarity, with Morimoto and Akiyuki firmly at the center of the burgeoning resistance (fig. 7). Thus, the strike begins in the Manga de dokuha adaptation.

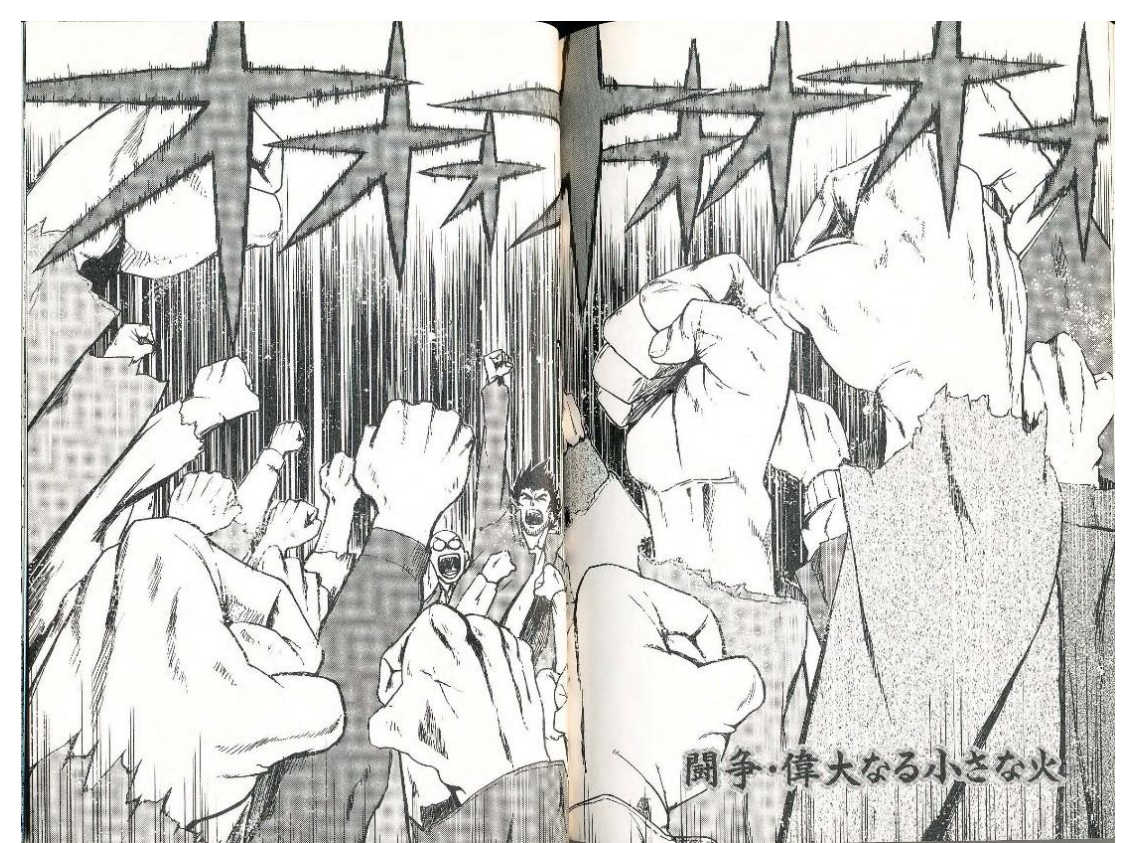

Figure 7. Morimoto and Akiyuki at the center of the resistance in Manga de dokuha.

When the strike goes underway, "aspect-to-aspect" transitions are utilized to

${ }^{54}$ Dokuha, 149. My translation. 
emphasize the nature of the two opposing forces at the center of this conflict. On one side we have Morimoto, whose words and aura have an ineffable power to mobilize his comrades, while on the other side there is Asakawa, wielding fear and violence to manipulate the workers. Thus, the focal point of the conflict can be found in the greatest weapon each side has at their disposal: Morimoto's charisma vis-a-vis Asakawa's capacity for violence. In the flurry of activity surrounding the strike, the manga lingers on these qualities of the principal characters to amplify the tension in this dialectic of oppressor and oppressed.

The strike scene opens with the group heading towards Asakawa's office. Interspersed with the action is the first "aspect-to-aspect" transition we find in this scene. It begins with a panel showing Asakawa reaching for his gun, followed by a close-up on his fingers as they near the trigger (fig. 8). The effect is one of increasing tension coming from the threat of direct violence from Asakawa. In the novel and in the adaptations as well, it is made clear that the workers

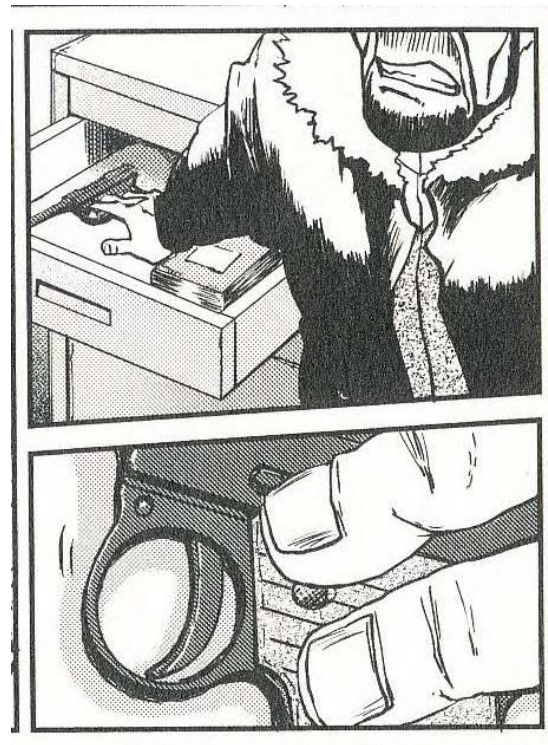

Figure 8. Asakawa reaching for his pistol. are careful not to cross Asakawa due to his capacity for violence, not to mention he is the only person on board in possession of a firearm. This point is also brought up earlier when the laborers are discussing whether to strike or not, with some of them fearing for their lives should they revolt against Asakawa. The gun thus serves as the nucleus of Asakawa's power aboard the ship. 

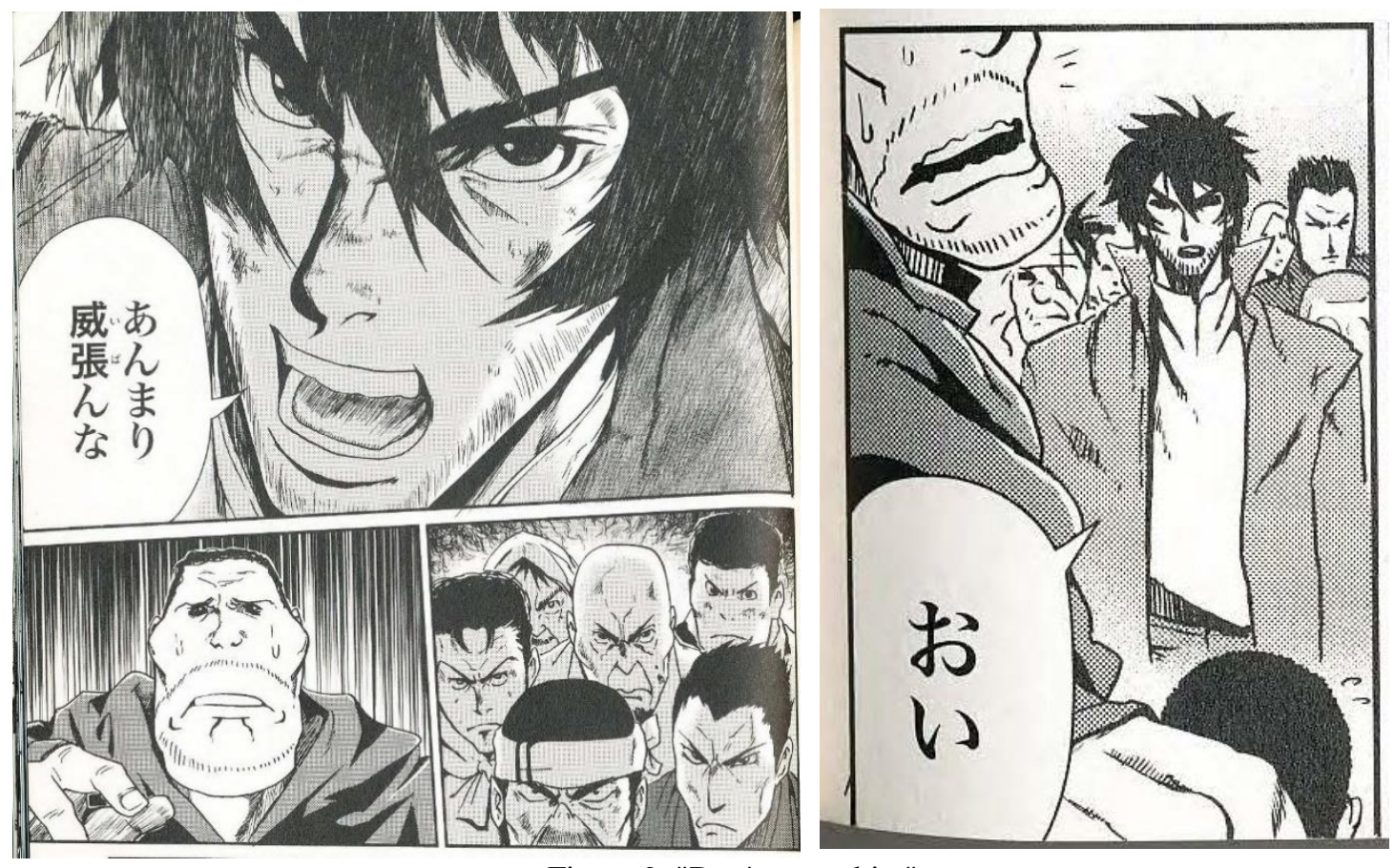

Figure 9. "Don't act so big."

However, another close-up takes place at the bottom of the same page leading into the top panel on the next page. Here, too, "aspect-to-aspect" transitions are used to focus on the arresting power behind Morimoto's warning to Asakawa's oversized underling, "Don’t act so big" (fig. 9). His look coupled with these words is enough to render the foreman impotent in the face of the striking workers. Here, "aspect-to-aspect" transitions add weight behind Morimoto's words, emphasizing not only their mobilizing (in this case de-mobilizing) power but also make clear the qualitative difference between Morimoto and Asakawa's ability to influence the people around them. Indeed, Morimoto's words possess an almost supernatural ability to inspire the workers to continue to resist despite the threat it may pose to their lives. Aside from these two instances, the rest of the scene is dominated by either "subject-to-subject" or "action-to-action" transitions showing how the throng led by Morimoto eventually makes its way into Asakawa's office to present a 
sheet of their demands.

The scene then returns to the "shit-hole", where the men are celebrating the day's activities as a success. ${ }^{55}$ However, the feeling of celebration is tempered by a lingering sense of doubt on the part of

Morimoto. Several panels focus on him sitting alone in quiet reflection (fig. 10). There is clearly something on his mind that prevents him from enjoying the festivities with his comrades. Again, "aspect-to-aspect" transitions
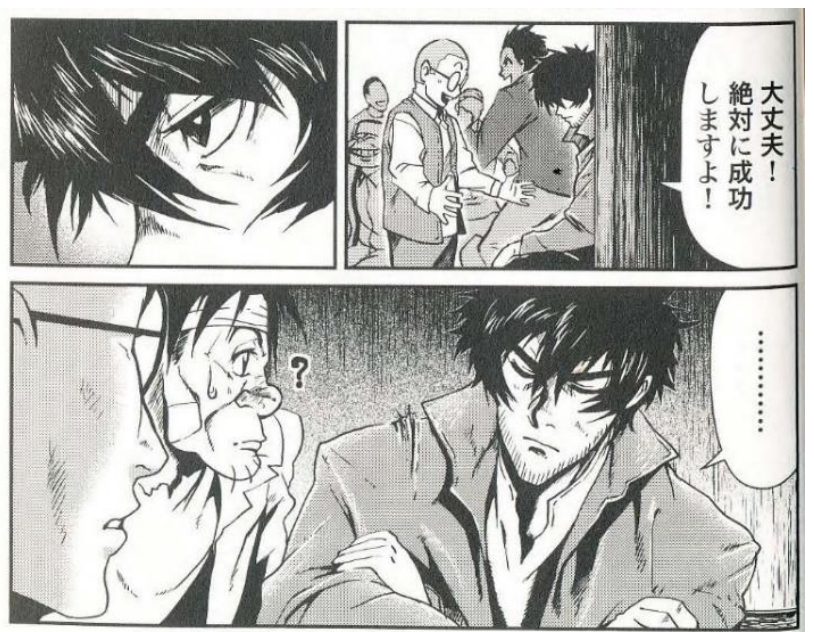

Figure 10. Morimoto in quiet reflection. are utilized to amplify this mood via another close-up of Morimoto. Panel 1's transition to panel 2 works much like a close-up. Panel 3 reinforces that silent moment. All three add up using "aspect-to-aspect" transitions of a somber mood of doubt.

The next day, the men and Asakawa meet on the deck of the ship to discuss terms. Some workers notice that the Naval destroyer has dispatched smaller ships heading their way. The excitement is palpable, with some men in tears at the fact that the military has come to their aid. Unfortunately, for the workers, this is not the case. The suppression is swift and violent, with "aspect-to-aspect" transitions used exclusively to express this moment. ${ }^{56}$ A splash covers the top third of both pages, overflowing with the snarling

\footnotetext{
${ }^{55}$ Refers to the fishermen's quarters aboard the ship. Written as kuso tsubo (粪壹, lit. 'shit-jar') in the original and adaptations, the place described as thick with tobacco smoke, body odor, and smells like a toilet (The Crab Cannery Ship, 25-26).

${ }^{56}$ Ibid., 162-163.
} 
faces of soldiers, rifles in hand (fig. 11). In the bottom panels, readers see the leaders of the resistance from behind with action lines rushing towards them indicating that they have been caught totally unawares (which is surprising considering the commotion their comrades were just making). The panel is followed by another depicting countless bayonets with action lines indicating the direction they are being trained. This is followed by Morimoto, caught in the midst of turning around with a look of dread on his face, before another panel depicts the rushing footsteps of the soldiers who, readers will find when turning to the next page, have totally surrounded the leaders of the resistance. Indeed, the way in which the panels are organized drive home not only how unanticipated this turn of events was for the leaders of the resistance but also their sheer disadvantage in numbers. This latter point is especially clear in the transition between the panel showing numerous bayonets followed by Morimoto's lone face. All of this is done without explicit narrative signals to drive the story forward in a linear way. "Aspect-toaspect" panels, like these, slow down the story and force the reader to savor the moodin this case, the dramatic tension.

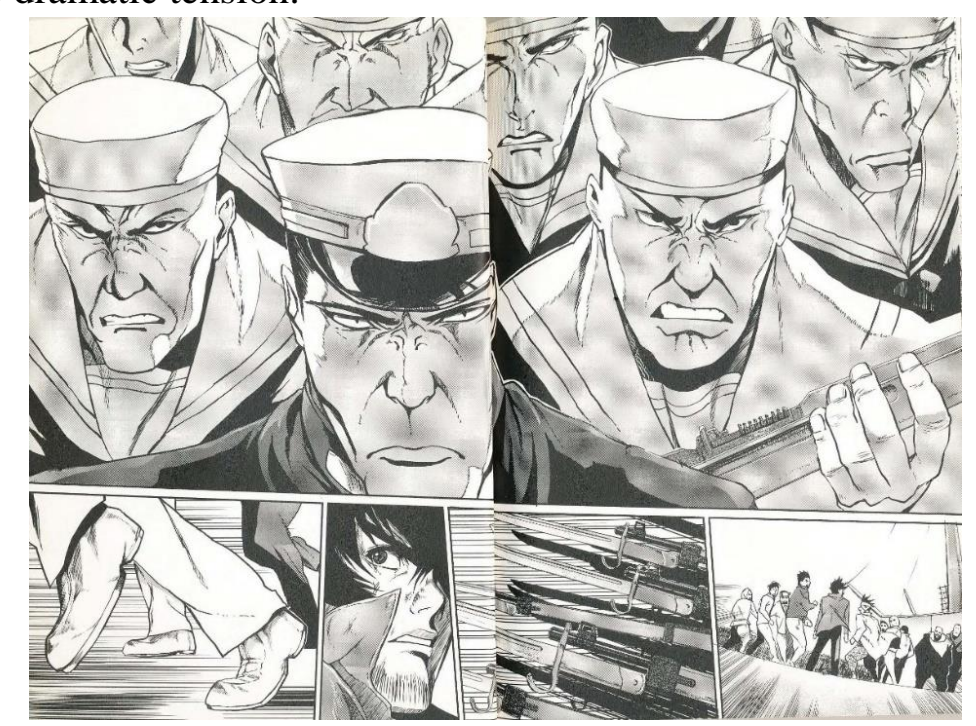

Figure 11. "Aspect-to-aspect" panels exploring the tense mood on board the ship. 
The following pages are dedicated to the Navy's merciless beating the leaders of the strike (fig. 12). This moment is also expressed through "aspect-to-aspect" transitions. Indeed, there is no particular linear quality to the scene nor much information indicating how long the beating went on. What is clear is how callous and unrelenting the Navy was in their treatment of the men, as well as the total dissipation of that intense spirit of defiance running through them when they stood face-to-face with Asakawa just moments ago.

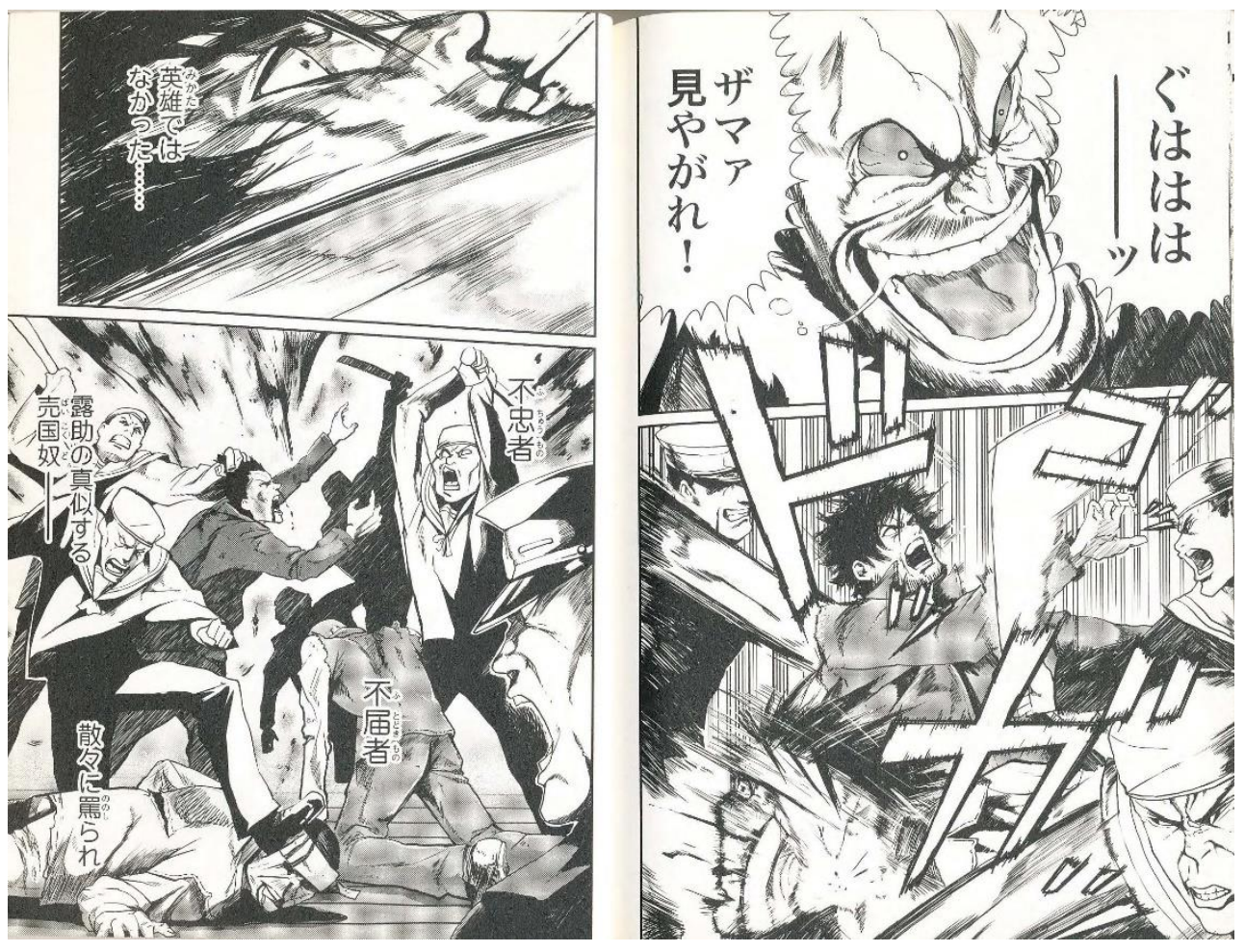

Figure 12. The resistance is crushed.

Following this scene, a panel captures a limp hand on the ground suddenly gain strength. This leads into the final confrontation between Morimoto and Asakawa. As usual, the Morimoto is at the center of the resistance. He is the last one to take a stand 
and, before Asakawa can draw his gun, Morimoto lands a punch drawn in the vein of the cross-counter made famous by Ashita no Joe. What's more, the following panels showing the elated faces of his comrades are reminiscent of excited spectators at a boxing match. The punch knocks Asakawa off his feet and, more importantly, flings his gun overboard. However, this celebratory moment is short-lived as Morimoto gets bludgeoned behind the neck by a rifle and ostensibly dies on the spot.

Here, a combination of "moment-to-moment", "action-to-action", and "subject-tosubject" transitions are used to express this final confrontation (fig. 13). After Morimoto rises to his feet behind Asakawa, we move to a panel showing Asakawa turning around in surprise, perhaps calling back to the moment when Morimoto was caught from behind by the Navy. A "subject-to-subject" transition is used to shift the focus from Asakawa to Morimoto, where we can clearly see the contrast between their facial expressions: Asakawa sports a look of dread whereas Morimoto has an almost quiet strength to his expression. The rest of the panel transitions leading up to the punch and its aftermath are a combination of "action-to-action" and "moment-to-moment". We see Asakawa reaching for his gun with a close-up as he almost fully draws it, followed by Morimoto's fist. Readers not only get a two-page splash of Morimoto's punch landing (fig. 14) but, on the following page, get to see Asakawa reeling from the sheer force of the blow, bent over backwards with his eyes rolling to the back of his head and blood spewing from his nose. The number of panels and pages dedicated to its buildup and aftermath, as well as the explicit use of linear panel transitions all indicate that this punch is the most important moment in the Dokuha adaptation. 


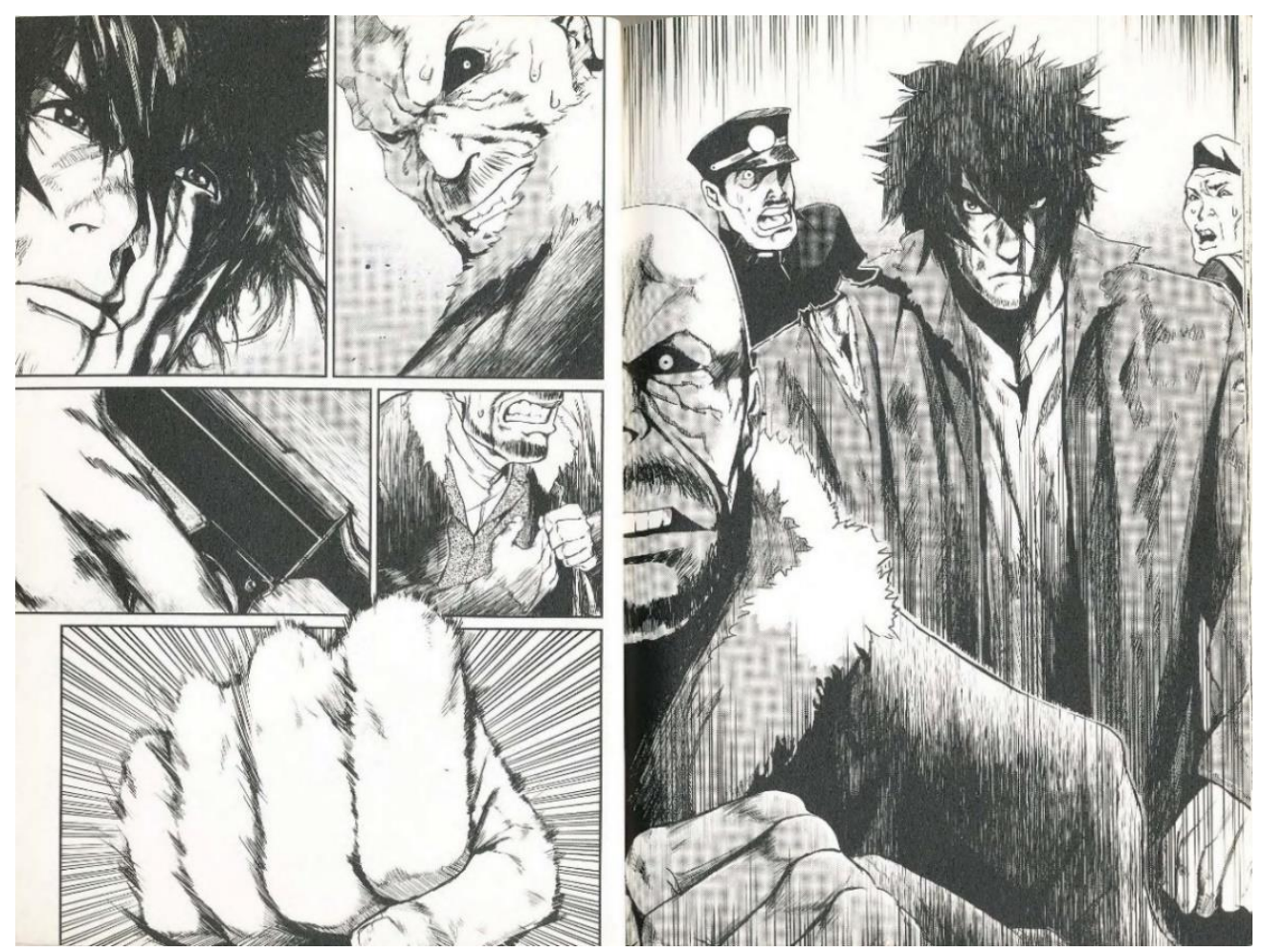

Figure 13. Morimoto's last stand.

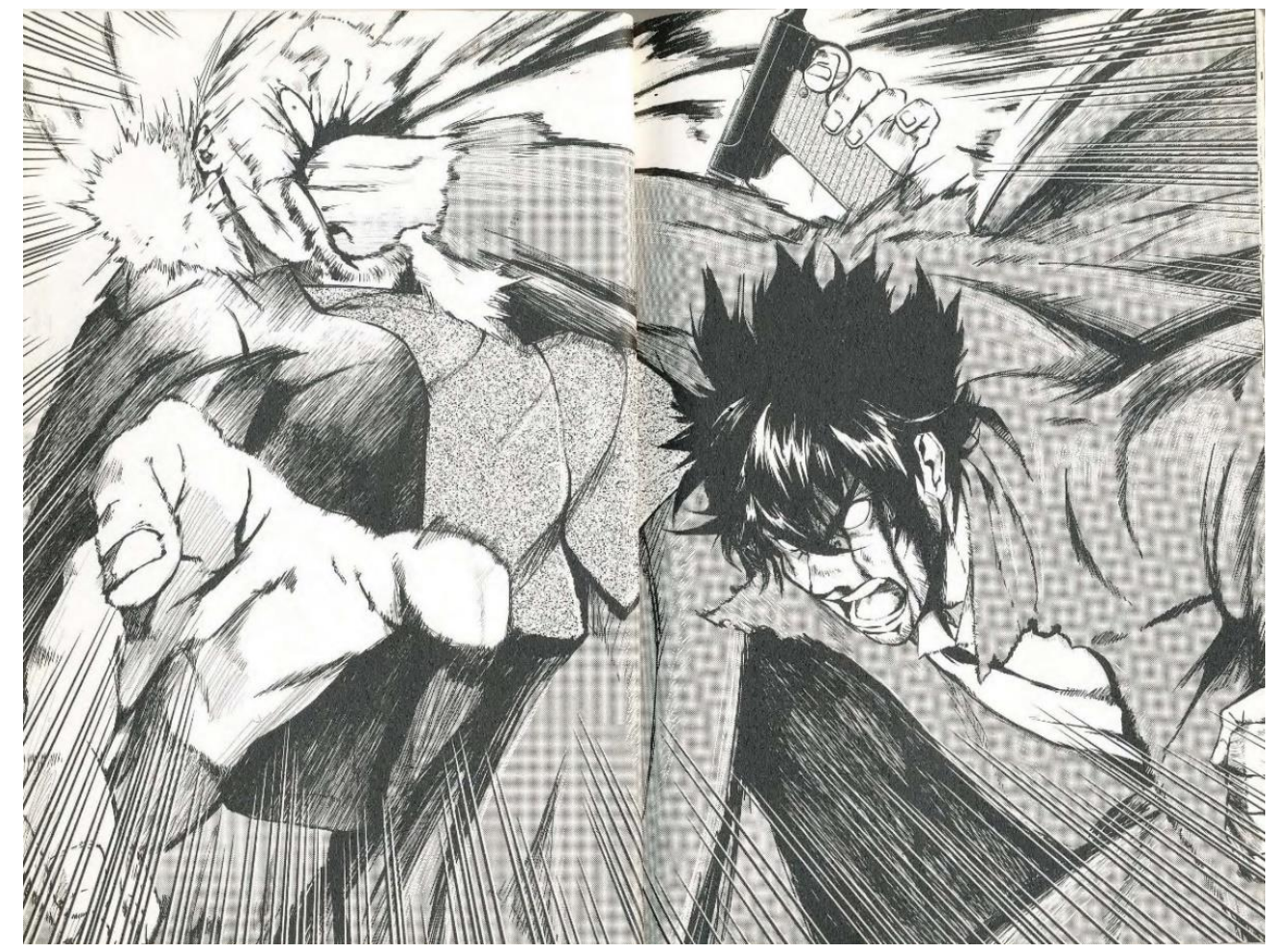

Figure 14. A two-page splash dedicated to Morimoto's punch. 
Despite losing his life, Morimoto takes away Asakawa's power during this violent confrontation. Without his pistol, Asakawa no longer possesses the very thing that prevented the workers from overtaking him by force in the first place. In later scenes Asakawa can be seen carrying around a bat, but this clearly is no replacement for his gun as the workers decide to strike again, this time with all aboard. Even Asakawa's underling musters up the courage to defy his boss and join the resistance.

While Dokuha may follow the general events of the original novel, there remains a nagging sense that if Morimoto had not sacrificed himself by punching Asakawa coupled with the luck of having his gun flung off-board, the remaining workers aboard would not be inspired to strike again. Indeed, their motivation appears to be based on the actions of a single comrade, rather than a knowledge of the various systems at work that continue to oppress the global proletariat. The number of panels and pages dedicated the actions of Morimoto throughout the work certainly suggest as much. However, Akiyuki's words say it all: "Morimoto's spirit became our courage." ${ }^{57}$ Notably, "spirit" in this instance is written with the same ideograms used for "spark" found in the Chinese idiomatic expression Morimoto recalled before the strike. Furthermore, the word for "our", or "all of us", is written with the ideograms classically used for the word "laborer" in Japanese. Thus, Morimoto is eulogized as the de facto savior of the laborers aboard the Hakkō-maru. As a result, the notion of collective action that forms the core of the original Kanikōsen is all but wiped away by Dokuha's end and is instead replaced by the unusual courage displayed by superhero Morimoto throughout the work.

${ }^{57}$ Ibid., 182. 


\section{Takiji Library}

While the Manga de dokuha adaptation uses the death of a fellow worker as the

tipping point for the ship workers, the strike as depicted in the original work has a

comparably benign catalyst: inclement weather. It is written as follows:

Triangular waves came rushing at the ship. Fishermen accustomed to the Kamchatka sea instantly knew what that meant. "No fishing today, way too dangerous." An hour went by. Men stood around in groups of seven or eight under the fishing boat winches. The boats swung in the air, each lowered only halfway. Men shrugged and argued gazing at the sea. A few minutes went by. "I quit! I quit!" "They can go fuck themselves!" It was as if they had been waiting for somebody to say it. As they jostled and milled about, someone else said, "Hey, let's pull the boats back up." "Yes!" "Yes, a damn good idea!" "But . .." A man looked up at the winch and hesitated, frowning. "If you want to drown, go out there by yourself!" said another scornfully, turning away with a jerk of his shoulder. The whole group began to leave. "I wonder if this is really OK," whispered someone. Two men uncertainly lagged behind. At the next pair of winches too fishermen stood motionless. Seeing the crew of Boat Number 2 walking toward them they understood what it meant. Four or five of them waved and raised their voices: "We're quitting! We're quitting!" "That's right, time to quit!" As the two groups met, their spirits rose..$^{58}$

While there is some doubt among a handful of workers about going ahead with the work stoppage, their reservations are quickly erased once they find other comrades on board with the strike. On this point, the Takiji Library adaptation is faithful to the original story but adds a new element of conflict among the workers in this scene.

\footnotetext{
${ }^{58}$ The Crab Cannery Ship, 86.
} 
In the Takiji Library adaptation, when the fishermen declare that they will not go out to sea, they encounter resistance from one of their supervisors. He insists that they send the boats out despite clear signs of a severe storm on the way, citing his apparent familiarity with the Kamchatka sea. ${ }^{59}$ This argument devolves into a physical conflict where he is struck in the face by one of the workers (fig. 15). Interestingly, and in direct contrast with what we saw in Dokuha, it is never made clear

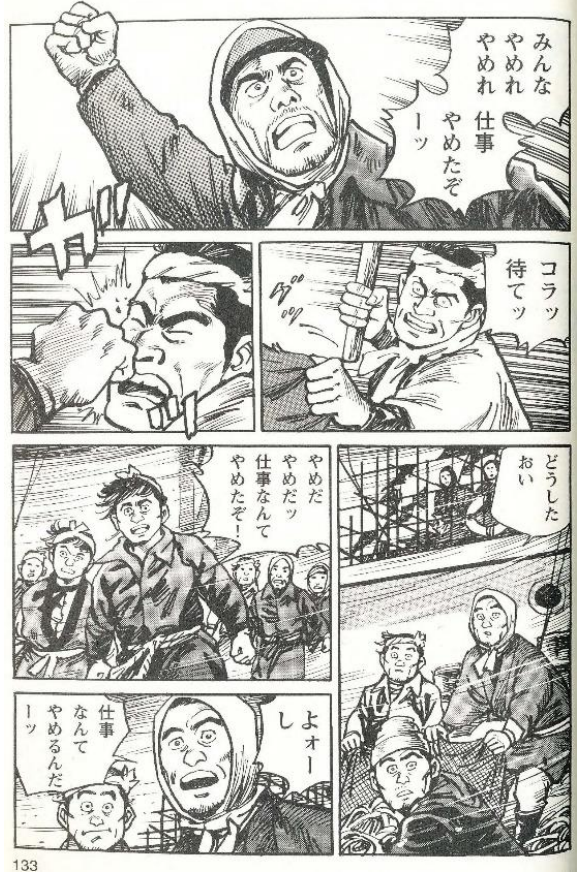

Figure 15. Who throws the punch? who actually hits the supervisor - the panel only shows a fist striking his face. One wonders why an otherwise faithful adaptation would add this conflict among the ship workers in the first place. On the surface, this choice comes off as a cheap strategy to make an old work appealing to a younger readership that may expect more scenes of action when reading a manga. However, the choice of not showing who throws the punch is how the Takiji Library distinguishes itself from the violence found in Dokuha and, to a greater degree, remains faithful to Takiji's message of collective resistance that permeates the original work.

As we saw earlier in the Manga de dokuha adaptation, the violent confrontations were all centered on the conflict between Morimoto and Asakawa, culminating into a climax that takes the form of a two-page spread showing a white-eyed Morimoto literally

${ }^{59}$ Takiji Library, 132. 
disfiguring Asakawa's face with a superhuman punch. In contrast, the violent confrontation found in the Takiji Library edition has no such focus; the fist that strikes the worker comes out of nowhere and nothing in the following panels indicate who threw the punch. Instead, the focus is constantly shifting among different perspectives aboard the ship, leaving no clues as to who summoned the courage to strike their superior.

But how do we interpret an anonymous punch in the context of a larger resistance? A similar incident that recently caught the attention of mainstream media comes to mind. In the wake of the 2017 presidential inauguration, violent protests erupted in Washington DC, and major media outlets were quick to pick up on videos of protesters destroying public property and clashing with police. Among the footage of protestors destroying windows of coffee chains and banks, one particular video went viral: white supremacist Richard Spencer being struck in the face during an interview on the sidelines of the protest. It is still not clear who actually struck Richard Spencer but this incident brought national attention to an anarchist tactic called the black bloc. In an article for The Nation, Natasha Lennard, a self-described participant of a black bloc on inauguration day, explains that "[t]he black bloc is not a group but an anarchist tactic-marching as a confrontational united force, uniformed in black and anonymized for security. Once deployed, the tactic has an alchemic quality, turning into a temporary object - the black bloc." 60 While the workers aboard the Hakkō-maru may not be donned in all black, the anonymity of the one who struck their superior is preserved through their solidarity. After

\footnotetext{
${ }^{60}$ Natasha Lennard, "Neo-Nazi Richard Spencer Got Punched-You Can Thank the Black Bloc," The Nation, last modified January 22, 2017, https://www.thenation.com/article/if-you-appreciated-seeing-neonazi-richard-spencer-get-punched-thank-the-black-bloc.
} 
the confrontation, they indeed begin "marching as a confrontational united force," leaving whoever threw the punch to remain anonymous but accepting their action as a necessary part of the resistance against the systems of oppression that continually put their lives at risk. What lingers is the sense that any one of them could have thrown the punch and, should push come to shove, they are ready to do so again.

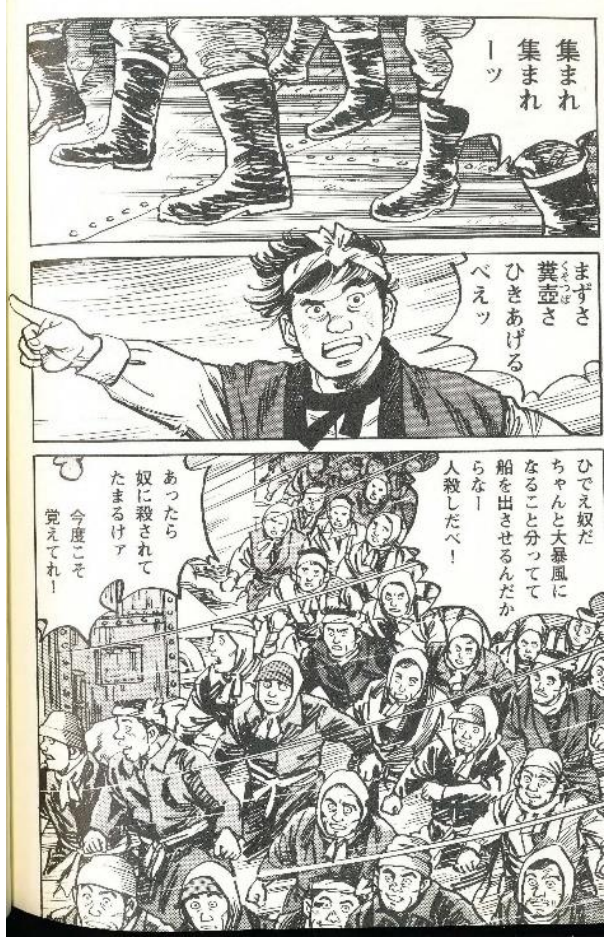

Figure 16. Collective boots, collective resistance.

This sense of collective resistance is continually amplified in the following pages, especially among panels connected by "aspect-toaspect" transitions. The page following the panel with the punch utilizes this particular type of closure to powerful effect. In the top panel, we are given a close-up of several feet marching in the same direction (fig. 16). The vantage point then moves to one of the leaders of the resistance pointing the way, followed by a wider shot of the frame showing just how quickly the multitude of deck workers have joined in the strike. In these three panels, readers can feel the growing momentum and solidarity among the ship workers, all of which seems to be happening almost simultaneously. The Takiji Library adaptation skillfully conveys the mood of the original novel with this use of "aspect-to-aspect" panels.

A similar type of closure once again comes into play when the workers have gathered on deck to hear speeches from representatives of each division of labor aboard the ship. Despite the scene being rich in dialogue, the vantage point shifts in each panel in 
order to place emphasis on not only on parts of the speech but also on the growing sentiment of collective resistance among those in the crowd. The scene begins with the point of view situated somewhere either behind or inside the crowd, before moving towards the speaker as he says, "Men, first and foremost, we must be united. No matter what happens we must not betray our comrades." An anonymous voice from the crowd counters with "If that's the case, then what's number two?!" The next panel zooms closer to the speaker's face as he responds with an impassioned, “And number two, we must be united!" ${ }^{61}$ In the following panel, the vantage point shifts behind the speaker, making visible the throng of ship workers clearly moved by his words. In this particular scene, the shifting vantage point among panels is deftly used in sync with the message the speaker is trying to convey: solidarity, above

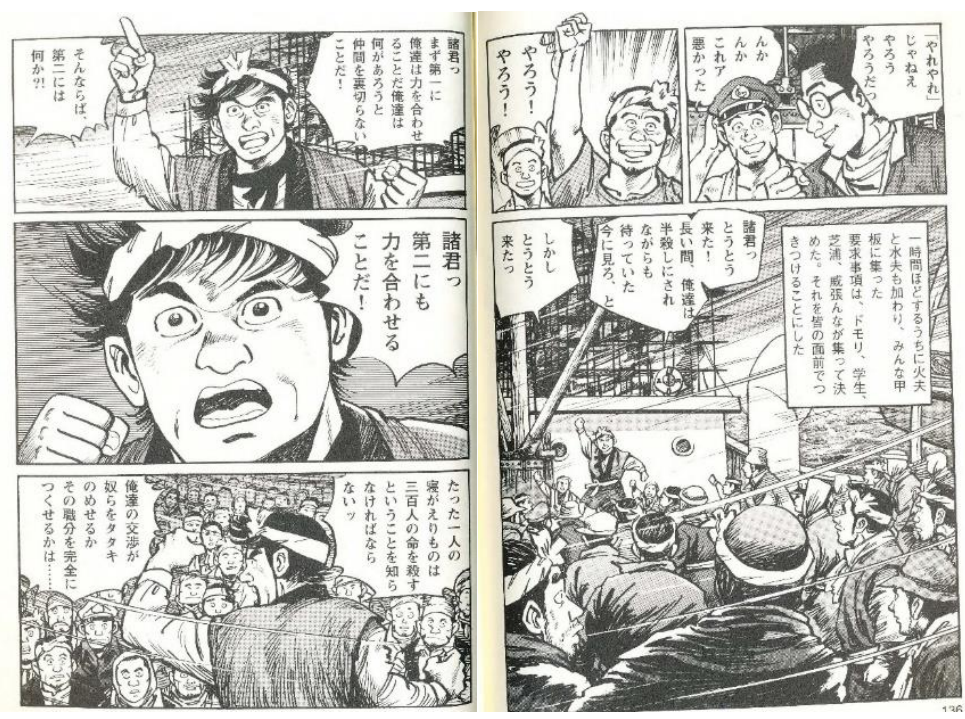
Figure 17. The "spinning camera" used to powerful effect. all, is what we need right now. And the way in which this message is illustrated between panels, zooming in on the speaker when he reiterates the necessity of collective resistance and then shifting the vantage point to show the faces of the workers gathered on the deck, effectively drives home the power behind his message and gives readers a sense that his words have

${ }^{61}$ Takiji Library, 137. My translation. 
resonated among the workers that have gathered there. While there is certainly a linear connection between these panels, this "spinning camera" effect is reminiscent of the "wandering eye"62 characteristic of "aspect-to-aspect" transitions (fig. 17).

Indeed, the most significant difference between this adaptation's handling of the strike scene and that of Manga de dokuha is the returning of the focus to the multitude. While the scene may begin with a single man, it does not linger on him in the way Manga de dokuha does. Furthermore, the worker giving the speech implores his comrades to band together, whereas Morimoto in the Manga de dokuha edition is almost entirely reticent throughout the scene until he explodes with the aforementioned "Now's the time to rise up. Those who don't want to die, come with me!"63 followed by a splash of him and Akiyuki surrounded by a crowd of anonymous fists raised in solidarity.

In the original work, this scene is almost entirely comprised of the speaker's dialogue, with no description of its effect on those listening beyond applause and light heckling:

"The most important thing of all, brothers, is to join forces and keep our power united. Whatever happens, we must never betray a comrade. If we just hang on tightly to that, they'll be easier to crush than worms. So, what's the second most important thing? The second most important thing, brothers, is also to keep our power united. Not to have anyone drop out. Not to have a single traitor, not a single turncoat. We must know that just one turncoat kills three hundred lives. One turncoat ..."

"We get it, we get it." Shouts interrupted him. "It'll be all right. Don't worry, keep going." "Whether we can beat them at negotiations, whether or not we can fulfill our task, all of that depends on the strength of our unity, brothers."64

${ }^{62} U C, 72$.

${ }^{63}$ Dokuha, 149. My translation.

${ }^{64}$ The Crab Cannery Ship, 89-90. 
The following speeches by other members of the group have a similar tone, with some speakers getting flustered about public speaking, sometimes being interrupted by their comrades. Indeed, Takiji's decision to avoid depicting the interiority of any characters makes it difficult to envision the impact of the speeches had on the listeners. However, the Takiji Library adaptation uses the visual language of manga - in specific, "aspect-toaspect" transitions - to inject emotional content into the scene.

Several speeches follow before the scene shifts to the crowd breaking into Asakawa's office (fig. 18). Again, "aspect-to-aspect" transitions are used, however this time in conjunction with “subject-to-subject" transitions to express not only the real danger these workers face when they confront Asakawa with pistol in hand but also the dynamism of the moment: it as though the balance of power is constantly shifting back and forth between the opposing sides of this conflict. ${ }^{65}$ In the succession of panels, we are initially shown the

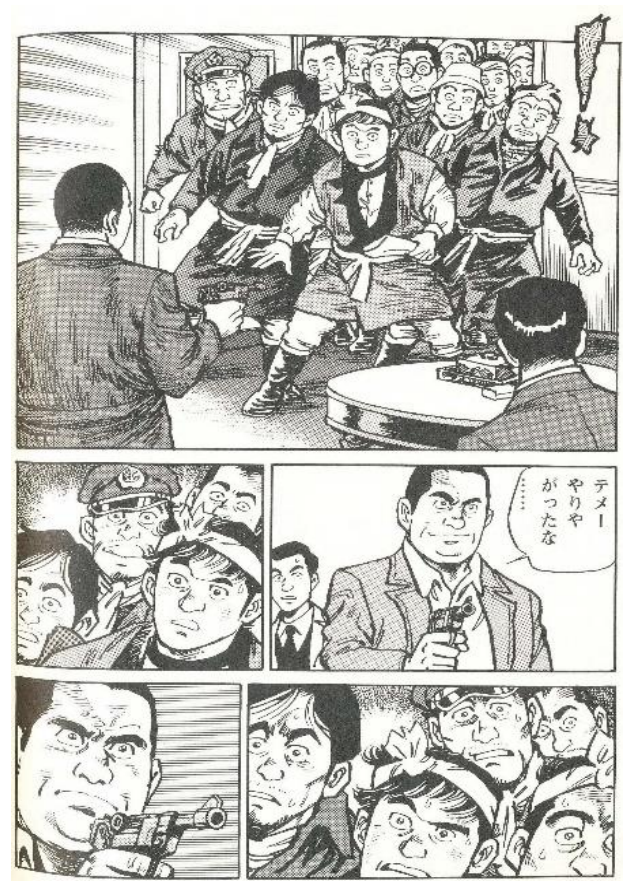

Figure 18. The delegates confront Asakawa. workers having burst through Asakawa's door with a look of utter surprise and Asakawa in foreground, pistol trained on the crowd. The following panels switch back and forth between Asakawa's face and that of the workers, gradually zooming in on their expressions. While the surprised faces of the workers remain consistent throughout the

${ }^{65}$ Takiji Library, 142. 
panels, in Asakawa's we

see a gradual change from

smug defiance to a grave,

dangerous expression. The

close-up of his face
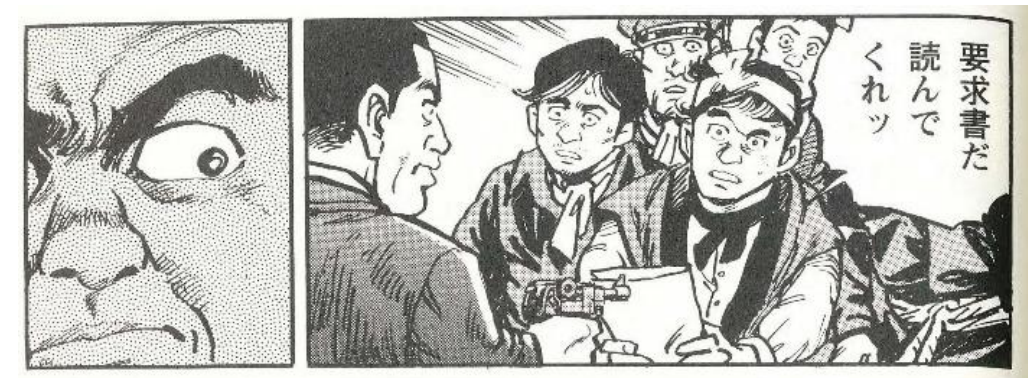

Figure 19. Asakawa's intimidating presence.

continues onto the next page, along with interesting stylistic choices within the panels.

For instance, one panel features a background comprised of bold lines and in the next panel of his face, Asakawa's face is shaded in with dots (fig. 19). These added details coupled with the zooming "aspect-to-aspect" and "subject-to-subject" transitions create a tense face-off. Indeed, a heightening sense of danger emanates from Asakawa, who can, at least temporarily, stop the workers in their tracks with his smug expression and pistol in hand.

The rest of the scene follows the novel closely. A worker, fed up with Asakawa's attitude, smacks the pistol out of his hand and strikes him in the face (fig. 20). This time, it is clear who throws the punch. Here, "aspect-to-aspect" transitions return the power of
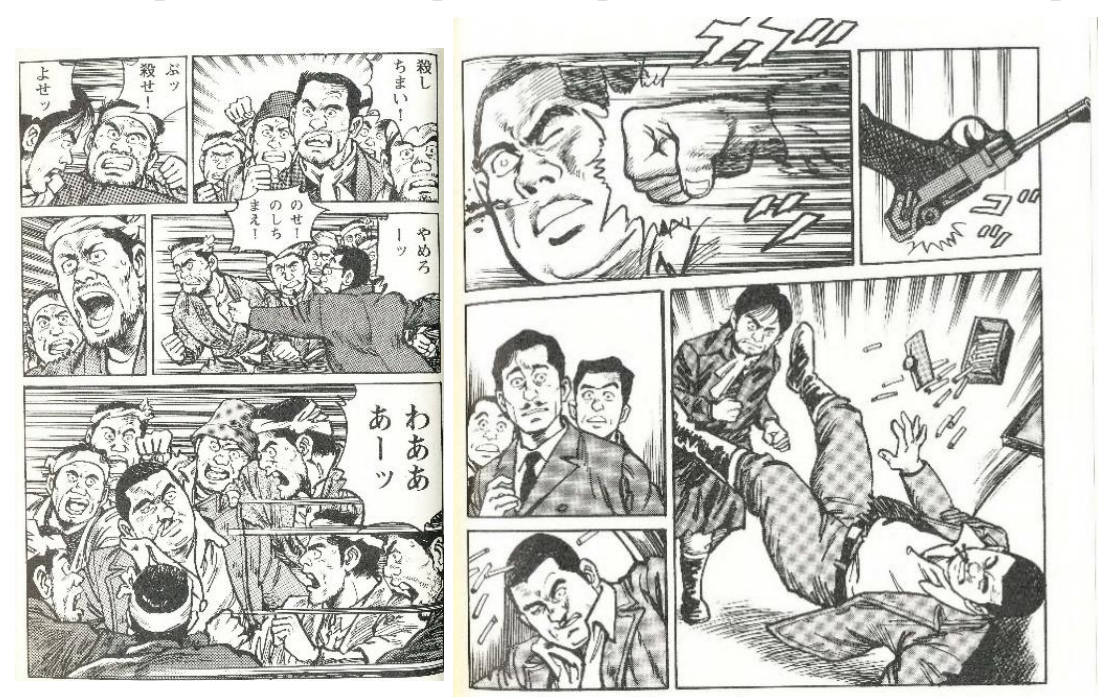

Figure 20. The fishermen have had enough. 
the scene to the striking workers. We see the man standing over Asakawa as he reels from the punch, followed by the horrified expressions of the captain, foreman, and factory agent, and finishes with another look at Asakawa in mid-fall, this time focusing on his dazed expression. Through "aspect-to-aspect" transitions, their spirit of defiance permeates the scene, and by its end we see all the workers crowding Asakawa, with it looking like everyone gets a piece of him. Thus, "aspect-to-aspect" transitions serve to highlight the significant ebb and flow in the balance of power between the workers and Asakawa.

The scene in which the Navy boards the ship is also expressed through a similar combination of "aspect-toaspect" and "subject-to-subject" transitions. True to the original narrative, the workers rush in excitement towards the edge of the deck to welcome their supposed saviors. However, much like we saw in the confrontation in Asakawa's office, there is again a backand-forth using "subject-to-subject" transitions, this time showing the crowd of excited workers against the

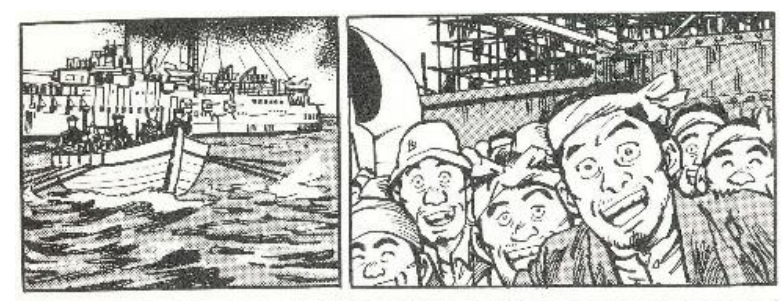

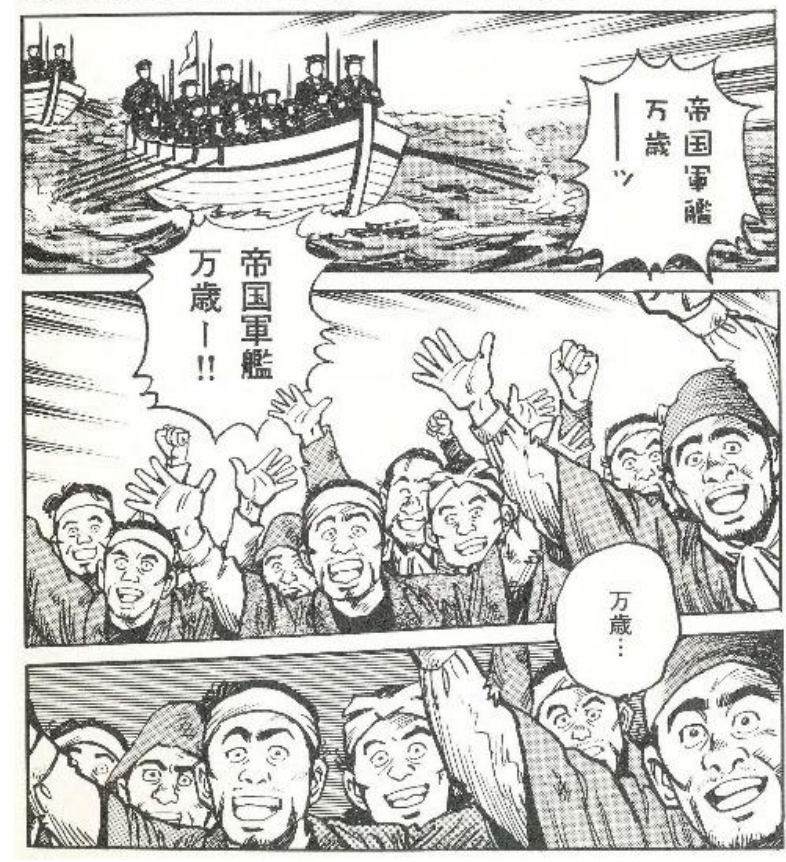

Figure 21. The elated faces of the ship workers. encroaching boats of soldiers (fig. 21). In the bottom panel, we once again find bold lines, this time foreshadowing the grim outcome that awaits the ship workers. It is 
immediately followed by a panel showing the Navy boarding the ship, sporting rifles outfitted with bayonets looking as though they are about to confront an enemy, not come to the aid of their fellow Japanese.

In the final moments of this scene we find a pair of close-ups of the leaders of the strike who have been rounded up, as well as the dumbfounded look of their comrades only able to stand by and watch as the strike ends in failure. ${ }^{66}$ Once again, a combination of "aspect-to-aspect" and "subject-to-subject" transitions are utilized to great effect, showing just how unexpected this turn of events was for the ship workers (fig. 22). Indeed, this series of panels adeptly captures the spirit of the scene as it is written in the novel:

They were not allowed to say anything. Denounced as "thugs," "subversives," and "Red traitors," the nine delegates were escorted to the destroyer at the point of bayonets. It all happened with lightning speed as the others watched in a daze, uncomprehending. Not a word of objection was allowed. They saw their efforts go up in flames as absurdly as a blazing sheet of paper. Their revolt had been disposed of with the greatest ease. ${ }^{67}$
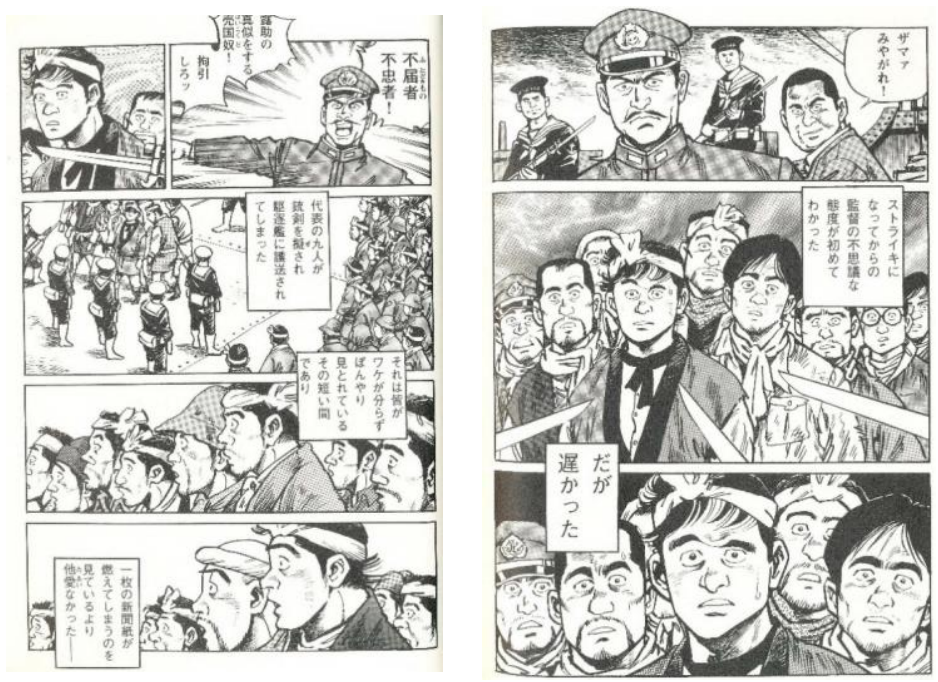

Figure 22. The delegates surrounded; the resistance quashed.

\footnotetext{
${ }^{66}$ Ibid., 152-153.

${ }^{67}$ The Crab Cannery Ship, 94.
} 
In terms of being faithful to Takiji's theory of collective action, perhaps the strongest argument can be made with the Takiji Library adaptation's use of "subject-tosubject" transitions in combination with "aspect-to-aspect" transitions. As illustrated above, even when this manga is attempting to convey a particular atmosphere or mood, it constantly returns the focus to the multitude of workers. We see them, time and time again, filling the panels when they are energized by the prospect of resistance or crestfallen by an unfortunate turn of events. Furthermore, this unified group is consistently shown in contrast with the singular Asakawa, especially at moments of severe agitation. In this regard, it is tempting to slightly expand on McCloud's type of closure, proposing the possibility of a "subjects-to-subject" transition. This is because the Takiji Library adaptation treats the group of ship workers as a visual subject in its narrative by consistently showing how the group, not just a single character, reacts to the developments that occur throughout the story. This treatment of the group as a subject once again demonstrates how the Takiji Library adaptation has been able to faithfully recreate the spirit of Kanikōsen through its visual design. The contrasting visual approaches displayed by the adaptations and their differing effects on the narrative remind us how meaning, in comics, is indeed as visual as it is textual. 


\section{On Content}

\section{Chapter 3 - The Path (Back) to Petit Bourgeois Realism}

Now that we have seen how the manga reimagined the formal aspects of Kanikōsen to varying effect, another aspect we can look at is how they adapt a crucial element of Takiji's literary style: his message of class struggle. The strike in Kanikōsen not only serves as the climax of the novel but also embodies this message. It is depicted as the outcome of two important factors: spontaneous organization in response to adverse working conditions and an emerging sense of class-consciousness via contact with "Red" ideas. These elements constitute the "groundwork" of the strike and also illustrate to readers how collective action can be achieved among a group of disorganized laborers. Class struggle and class consciousness are thus at the forefront of the narrative. However, the Dokuha and Takiji Library adaptations diverge from this point. Instead, collective resistance is grounded in humanitarian ideals informed by a fundamentally individualistic perspective, demonstrated by the way in which the adaptations appropriate, alter, or omit explicitly "Red" ideas from the novel. For major figures in the proletarian literary movement, these changes would indicate a step backward. In place of class struggle, class consciousness, and the fundamentally Marxist ideology of the proletarian literary movement, these two manga adaptations appeal to general notions of injustice and morality in response to societal issues. This chapter shows how the adaptations, despite being based on a novel representative of a movement that placed equal import on both the political and artistic, nevertheless demonstrate the modern-day Japanese public's aversion to politics during the time of their publication by foregrounding the humanitarianism of

\section{Kanikōsen.}


To contend that Takiji and many of the other proletarian writers were not motivated by humanitarian sentiment would be irresponsible. There must have been a profound love for humanity that inspired Takiji to work tirelessly not only as a writer but also as an activist for the sake of Japan's working class. Indeed, this sentiment is powerfully present throughout his work. But he and the other proletarian writers went further than simply depicting the plight of the lower class; proletarian literature was meant to be an education. As Field and Bowen-Struyk write:

Their love of literature had been a path to their awakening to social injustice, and it was not far-fetched for them to use it, in the venerable words of Horace about the nature of poetry, to "delight" and to "instruct," which here translated into giving the industrial workers and tenant farmers being robbed of their humanity the energy and dignity that come with the power to understand the makeup of the world. $^{68}$

The proletarian writers were thus concerned with not only creating art whose subject matter and intended readership was the working class but also using that art as means to teach readers about the social apparatuses that negatively impact their lives. Furthermore, proletarian literature could offer readers insight in how to effectively resist and overcome these mechanisms of oppression. In fact, Takiji himself stated that this is a vital part of Kanikōsen.

As mentioned earlier, upon publishing Kanikōsen, Kobayashi Takiji sent a letter of intent to Kurahara Korehito detailing seven specific aspects of the novel he found important. Komori Yōichi argues that "these seven points provide the most systematic

\footnotetext{
${ }^{68}$ Heather Bowen-Struyk and Norma Field, "Introduction" in For Dignity, Justice, and Revolution, ed. Heather Bowen-Struyk and Norma Field (Chicago: The University of Chicago Press, 2016), 9.
} 
and precise commentary on the basic characteristics and structure of the novel." ${ }^{99}$ Indeed, Takiji's letter not only allows readers insight into his authorial intentions but also provides a clear framework in which one can judge the faithfulness of the various adaptations in respect to the original work. In the letter, Takiji explains his reasoning behind formalistic choices such as the group protagonist and absence of detailed interiority or psychology, why he chose the setting of the crab-cannery ship, the significance of depicting unorganized laborers, and illustrates the irony of how capitalism, in its effort to keep workers unorganized, actually creates the conditions that inspires workers to spontaneously organize. However, it is the seventh and final point that is of chief concern here. Takiji writes:

七、プロレタリアは、帝国主義的戦争に、絶対反対しなければならない、 と云う。然し、どういうワヶでそうであるのか、分っている『労働者』は 日本のうちに何人いるか。然し、今これを知らなければならない。緊急な ことだ。

たら゙単に軍隊内の身分的な虐使を描いたら゙けでは人道主義的な憤怒 しか起すことが出来ない。その背後にあって、軍隊自身を動かす、帝国主 義の機構、帝国主義戦争の経済的な根拠、にふれることが出来ない。帝国 軍隊——財閥——国際関係—労働者。

この三つが、全体的に見られなければならない。それには蟹工船は 最もいつ舞台だった。

And seven, they say that the proletariat must oppose imperialist wars. However, just how many laborers in Japan know why that must be? Nevertheless, they must know this now; it is of the utmost importance.

${ }^{69}$ Komori Yōichi, "Introduction" in The Crab Cannery Ship and Other Novels of Struggle (Honolulu: The University of Hawai'i Press, 2013), 7. 
Simply depicting class-based physical torture within the military can only stir up humanitarian sentiment. It does not address the imperialist mechanisms and economic foundation of imperialist war that mobilize the military. The imperial army — the zaibatsu — international relations-laborers.

These three aspects ${ }^{70}$ must be seen from a holistic perspective. The crab cannery ship is the perfect setting for that purpose..$^{71}$

Takiji's message is clear: he wanted his intended readership — the proletariat — to understand why they must be against imperialist war. A simply humanitarian, anti-war stance is insufficient. Thus, one of Takiji's major goals for Kanikōsen was to accurately depict how the military, government, and imperial family construct and sustain adverse living conditions for the proletariat. After reading Kanikōsen, he wanted his readers to be able to grasp the true nature of these mechanisms and acquire the power that comes with this knowledge. Therefore, he felt the necessity to create a narrative that goes beyond engendering "humanitarian sentiment" within the reader. In fact, Takiji's intentions reflect the broader goals of the proletarian literary movement at that time. However, in order to attain such goals, proletarian writers and critics found it necessary to "redefine the form and function of literature and art." 72 To this end, Kurahara Korehito conceptualized what he calls proletarian realism.

In "The Path to Proletarian Realism” (1928), Kurahara establishes three different types of realism — modern (or bourgeois) realism, petit bourgeois realism, and proletarian realism - to promote ideological and creative unity within the proletarian literary

\footnotetext{
${ }^{70}$ It should be noted that this is a typo on Takiji's part, as pointed out by Professor Ogino Fujio at the 2016 Takiji-sai in Otaru, Hokkaido.

${ }^{71}$ Kobayashi Takiji, "Sen kyu hyaku ni jū kyū nen san gatsu san jū ichi nichi Kurahara Korehito ate," in Kobayashi Takiji Zenshū, VII (Tokyo: Shin Nihon Shuppansha, 1993), 392-3. My translation.

${ }^{72}$ Heather Bowen-Struyk, "Introduction: Proletarian Arts in East Asia," positions: east asia cultures critique 14, no. 2 (2006), accessed August 12, 2017: 251-278, doi: 10.1215/10679847-2006-002.
} 
movement. The essay not only defines the three types of realism but also clearly delineates what differs among them. Bourgeois realism, for instance, is fundamentally informed by a biological notion of "human essence" and abstracts the individual from reality and social conditions. ${ }^{73}$ Kurahara contends that this emphasis on the isolated individual's experience vis-a-vis reality is insufficient as a form of realist art as it does not depict how the individual is shaped by their position in society. On the other hand, petit bourgeois realism does "take a stand in regard to society" but is nevertheless informed by an individualist perspective. ${ }^{74}$ Furthermore, petit bourgeois realists appeal "to abstract ideas of justice and morality for solutions to social problems" promoting a "viewpoint on society [that] stresses class cooperation."75 This notion of class cooperation is particularly contentious for Kurahara as he argues that proletarian realism is all about class struggle. He writes, "what spurs social progress, however, is not cooperation between classes but the public and not-so-public conflicts between them, a fact easily proven by the course of history itself."76 Thus, for Kurahara, class struggle and class consciousness are at the core of what makes a successful work of proletarian realism.

As discussed earlier, Kurahara had reservations about Takiji’s experimental group protagonist in Kanikōsen. That being said, the novel's emphasis on the cast of laborers and their experience of reality as a member of the proletariat, plus the detailed depiction of the mechanisms that contribute to their oppression, make the novel an exemplary work

\footnotetext{
${ }^{73}$ Korehito Kurahara, "The Path to Proletarian Realism" in For Dignity, Justice, and Revolution, ed. Heather Bowen-Struyk and Norma Field (Chicago: The University of Chicago Press, 2016), 177.

${ }^{74}$ Ibid., 175.

${ }^{75}$ Ibid., 178.

${ }^{76}$ Ibid., 178.
} 
of proletarian realism. What should be noted, however, is that several key scenes that foreground these aspects often include the most explicitly political moments in the narrative, especially those that comprise the groundwork of the strike. Notions of class consciousness and class struggle are thus inextricably linked to the fundamentally Marxist politics of Kanikōsen. However, it is precisely these scenes that are altered or omitted in the manga adaptations, producing a narrative that places emphasis on the humanitarian tendencies emblematic of petit bourgeois realism. Before comparing these scenes in the original and the manga adaptations, it may be helpful to illustrate how the politics of Kanikōsen and Takiji himself have influenced the public's reception of the novel.

Political activism and debate have largely been avoided by the general Japanese public since the 1970's. Norma Field succinctly describes this mood when discussing the improbability of the Kanikōsen boom in 2008:

In Japan, it is generally acknowledged that "the season of politics" was over by the early 1970s, after both the popular struggle against the renewal of the U.S.Japan Security Treaty in 1960 had been crushed and the student struggle of 196870 , which was an explosive protest against the bureaucratized, competitive, consumption-centered society that had followed upon the "income-doubling" plan announced in 1960, ended in a widespread sense of defeat. What did this mean for the legacy of a writer like Kobayashi Takiji? At the time of his death at age 29 by torture at the hands of the Special Higher Police, he was a member of the then illegal Japan Communist Party. Leftist intellectuals from the 60s and 70s movements, who might be thought to feel some affinity for him, were alienated by the fact of his membership in a party that had sought to control them. For others, saturated in postmodernist ideology, a body of works produced in a classbased revolutionary movement was simply laughable. But surely there was more to the hostility of middle-aged leftists than party affiliation or intellectual camp. 
Takiji's name awakened an all but forgotten reconciliation with a retreat from politics. It registered as a dull, irritating reproach. ${ }^{77}$

Indeed, the resurgence of Kanikōsen seems all the more unlikely during an era in which the general public preferred to avoid open discussion of leftist politics. However, it should be noted that the Takiji Library and Dokuha adaptations were first published prior to the boom, in 2006 and 2007 respectively. In fact, according to Field, the Takiji Library manga adaptation was part of "several developments laid the ground for expanding interest in Takiji beyond the tiny circles of devotees."78 Whereas it appears that the Dokuha adaptation was part of a larger business model that had the timely insight to publish an adaptation during a period when terms like “" [w]orking poor’ (wakingu pu-a), "divided society" (kakusa shakai) and "precariat" (a neologism combining "proletariat" and "precarious")" were buzzwords in Japan. ${ }^{79}$ Nevertheless, the two adaptations were published during a period in time when politics, especially radical left-leaning politics like Takiji's, did not have a place in the Japanese mainstream. Thus, the diversions from the original narrative in the adaptations appear to reflect the zeitgeist during their time of publication. However, the politics of Kanikōsen invited debate long before Japan's "Season of Politics."

While praised by Marxists during its time of publication, those not strictly affiliated with leftist movements attacked the political aspects of the novel. In a letter sent to Takiji, Shiga Naoya "praised the story, but insisted that a work of literature must move

\footnotetext{
${ }^{77}$ Field, "Commercial Appetite and Human Need."

78 Ibid.

${ }^{79}$ Bowen-Struyk, "Why a Boom in Proletarian Literature in Japan?"
} 
the readers directly and not by the ideological convictions it indirectly conveys[.]"80 Furthermore, in Donald Keene's own appraisal of the novel, he writes that "the sections of The Factory Ship in which Communist party doctrine is openly stated are embarrassingly inept. But no doubt it was precisely those places that mean most to the author." 81 Thus, the explicitly political elements found in Kanikōsen have either been praised or seen as a weak point of the novel depending on how his critics viewed the relationship between art and politics. As a work from the proletarian literary movement, where the artistic and political are one and the same, Takiji's politics are essential to the novel. Furthermore, they constitute a crucial part of the logic of the plot, as they form the groundwork that precedes the strike. Several scenes in the novel illustrate this point.

The "Stranded in Russia" scene is perhaps the most politically explicit moment in the text. In the scene, Asakawa sends fishing boats out to sea despite receiving gale warning from another ship anchored nearby. One boat does not return from the storm and the men are thought to have been lost at sea, never to return. However, the boat makes an unexpected return days later with all the men alive and well. Once aboard, the fishermen tell of how they washed up on the Kamchatka shore and were rescued by Russian villagers living nearby. The Russians kindly took them in and they spent two days recuperating and enjoying themselves. On the day they were set to return to the cannery ship, several Russians accompanied by a Chinese man met with them. Using broken Japanese and physical gestures, the Chinese man explains to the fishermen that they are the proletariat. He attempts to awaken class-consciousness within the fishermen:

\footnotetext{
80 Ibid.

${ }^{81}$ Keene, Dawn to the West, 619.
} 
"Rich mans do this all you." (He grabbed himself by the neck, as if in a chokehold.) "Rich mans get more, more big." (He indicated an expanding stomach.) "All you, no good, get more, more poor. Understand? Japan, no good. Working people, this." (He frowned, making a face as though he were ill.) Rich man boss, this. Ahem. Ahem." (He strutted about). ${ }^{82}$

The Chinese man explains to the fishermen how a minority of wealthy capitalists, in collusion with the government, military, and imperial family, exploit labor from the proletariat, reaping exorbitant profits and living in luxury while the workers of Japan are left in destitution. In the midst of this conversation, the fishermen realize that this "is probably what was meant by the 'terrible' phrase 'turning Red." 83 However, rather than dismissing the man outright, most of the fishermen eventually agree with him before finally becoming enthusiastic about the prospect of a workers' revolution. The sole exception being the boat boss, who sees this as "Russia's crafty way of deceiving Japan." ${ }^{84}$ When the fishermen relate this incident to their fellow workers aboard the ship, they too become absorbed into the story. However, the boat boss, sensing danger in these ideas, cuts the fisherman short when he sees how intently the other men are listening to this account. Notably, this is the only scene in the novel where the word "proletariat" is used. By coming in contact with the Chinese and Russians, the fishermen, a disorganized group of seasonal laborers from various regions of Japan, learn that they are in fact part of a social class: the proletariat. Furthermore, they begin to understand just what kind of power the proletariat can possess simply through this realization. The danger the boat

\footnotetext{
${ }^{82}$ The Crab Cannery Ship, 45.

${ }^{83}$ Ibid., 46.

${ }^{84}$ Ibid., 47.
} 
boss senses in these ideas speaks to their truth; the workers of Japan could be a force to be reckoned with should they develop a sense of class-consciousness.

This scene may fall into Keene's critique as it is so explicit in expounding the basic tenets of the Communist party. While Keene may have considered this a weak point in the novel, Takiji's use of the Chinese man as a vehicle for transmitting this doctrine can also be seen as a clever way to communicate directly with his intended readership, the Japanese proletariat. By creating a character whose command of Japanese is limited, he can hone in on the essence of the message he is attempting to convey. For the proletarian writers, the importance of using simple language cannot be overstated, as they were concerned with how to develop a means of "writing that would reach readers of widely divergent literacy." 85 They set out to create pieces that stood on their own as literary works of art but were also accessible to a potential readership that may not have had equal access to higher education. As mentioned earlier, the proletarian writers sought to "delight" and "instruct" their readership. While the passage in question may not have been a "delight" for some, it is certainly instructive in its use of clear, precise language to illustrate the plight of the proletariat during that era in Japan. Furthermore, it serves as one of the important factors that leads to the awakening of class-consciousness among the ship workers in the novel. Indeed, this encounter with the Russians functions as a major part of the "groundwork" of the strike.

The Dokuha adaptation offers a relatively faithful reimagining of this scene. The Chinese man is shown using a mix of physical gestures and rudimentary Japanese as he

${ }^{85}$ For Dignity, Justice, and Revolution, 1. 
explains to the fishermen who the proletariat are, how they are exploited by the wealthy, and that the workers of Japan can create a more equal society by banding together. Like in the novel, the term “turning Red” (seki-ka, 赤化) emerges here when the fishermen start commenting on the Chinese man's speech. Their previous conception of "Red" ideas and their emerging sense of class-consciousness is illustrated within the space of a single page (fig. 23).

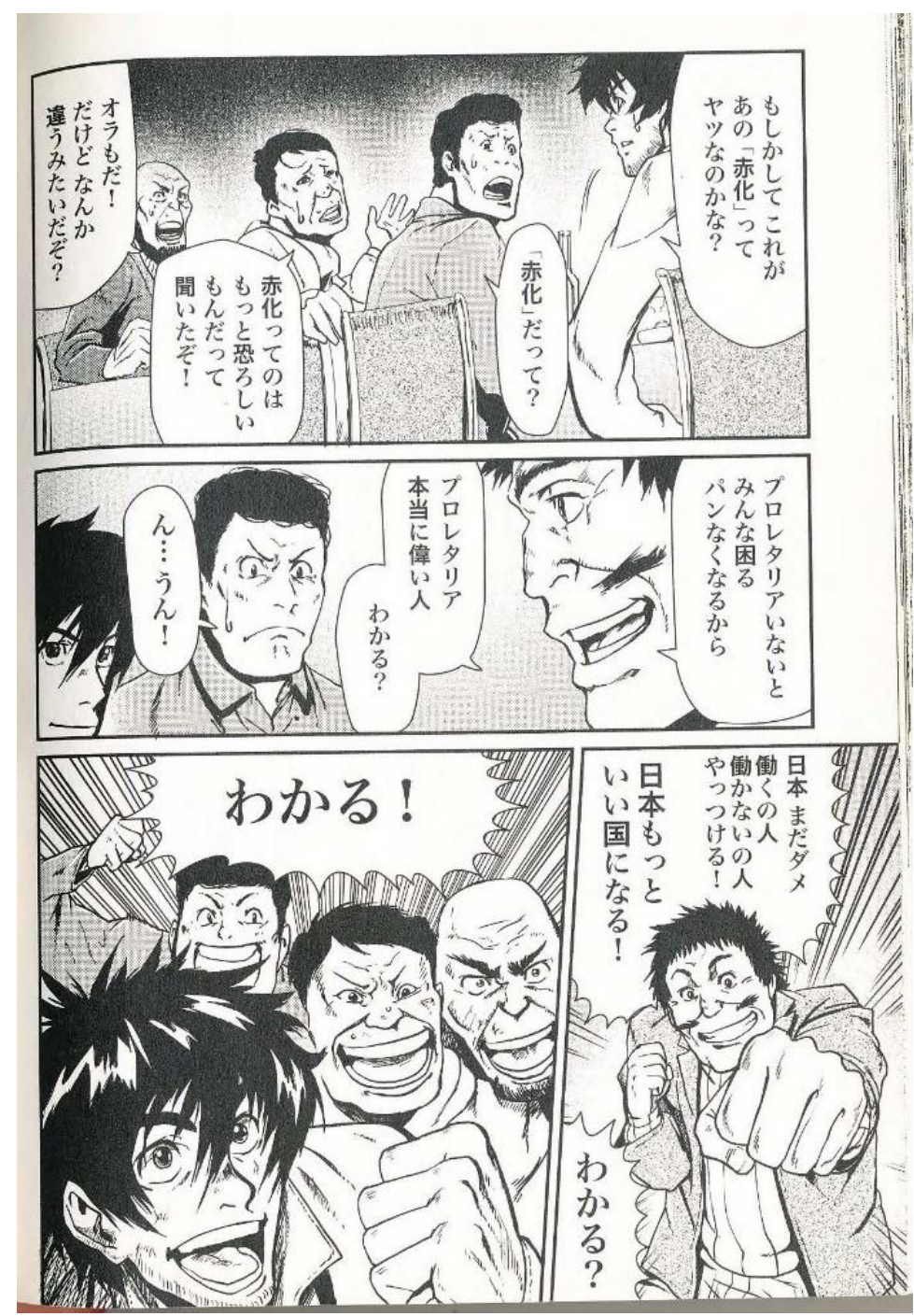

Figure 23. In Dokuha, sometimes class-consciousness comes easy. 
Any doubts they may have harbored towards "red" ideas are quickly erased, and it becomes clear that they have fully accepted this doctrine of the Communist party. Upon returning to the cannery ship, the men relate the story to their fellow workers, setting off a chain of events that lead to Morimoto leading the strike. Thus, the Dokuha adaptation does stage the "Stranded in Russia" scene as a fundamental part of the narrative (much like the original). However, the narrative of the manga does not make any indication that any other fishermen held onto these ideas of class-consciousness and struggle in any significant way. Instead, Morimoto's decision to strike comes precisely after a scene that shows him reminiscing on a moment when he and the Chinese man spoke privately. Thus, the narrative is firmly rooted in an individualistic perspective as it places emphasis solely on Morimoto's experience and internal change from this encounter. As a result, despite adapting the scene in a somewhat faithful manner and retaining some politically loaded terms, its inability to rise beyond an individualistic focus prevents the Dokuha adaptation from satisfying the requirements of a successful work of proletarian realism. However, the Takiji Library's take on this scene could not be more different: the ship remains lost at sea with its crew never to return (fig. 24). ${ }^{86}$ Before discussing the implications of this omission, it may be helpful to examine how another scene in the novel that incorporates "Red" content is contextualized and adapted.

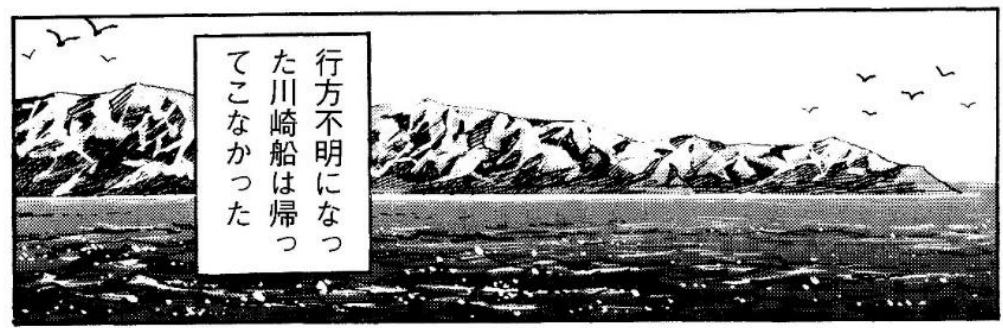

Figure 24. The panel narrates, "The missing boat did not return."

${ }^{86}$ Takiji Library, 60. 
Sensing that their bodies can no longer handle the overwork, some men begin to decrease the pace of their work despite the threat of violence from Asakawa; they have begun a work slowdown without fully realizing it. They gradually start to coordinate their slowdowns and are surprised at its effectiveness. Other workers notice and join in. The coordinated work slowdowns are depicted as though they were a natural response to the adverse working conditions. It is as if the ship workers are beginning to organize without realizing it (fig. 25).

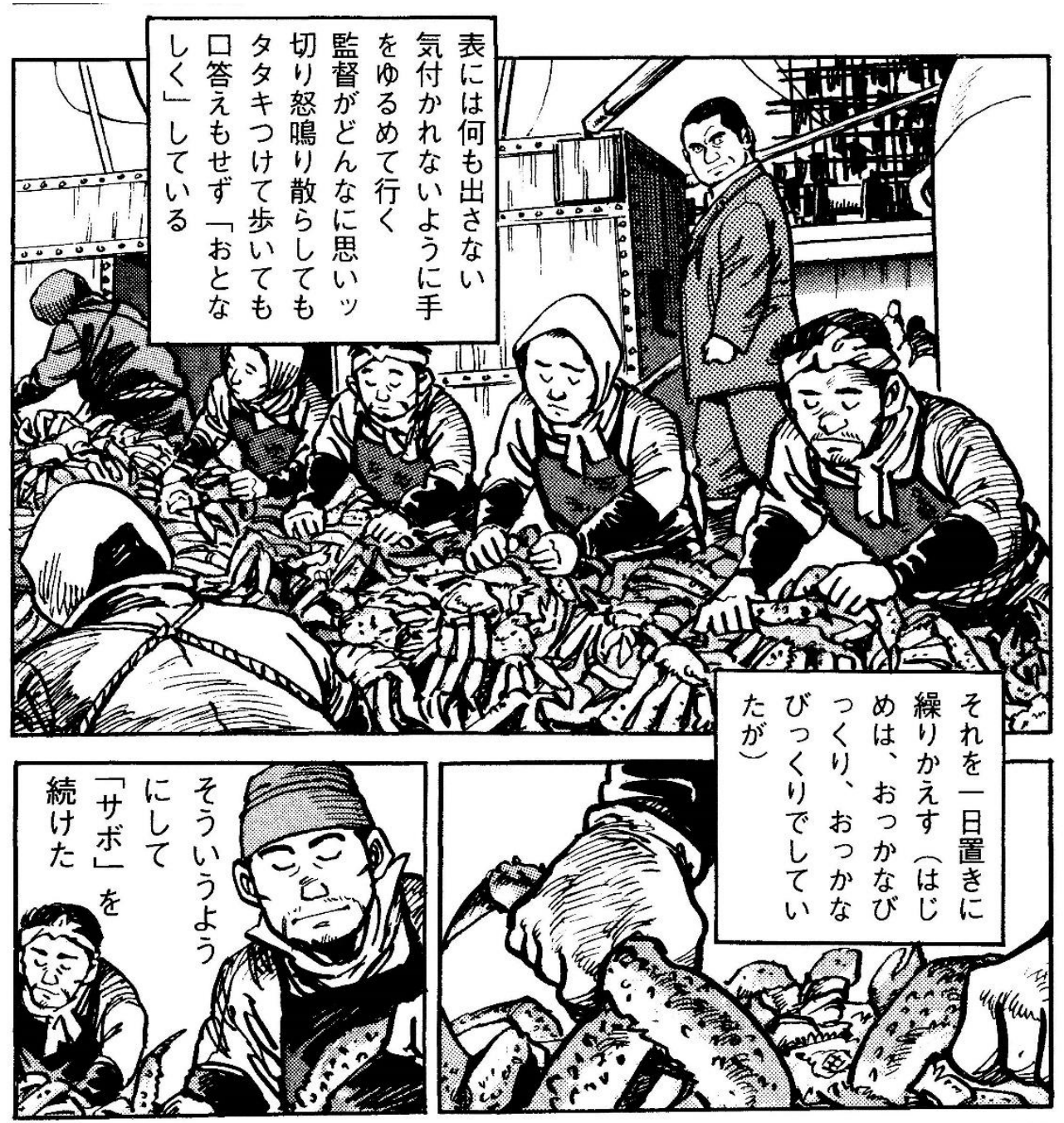

Figure 25. The slowdowns begin. 
Amid these slowdowns, the representatives that lead the strike in the climax also

emerge. Even this selection of representatives is seen as a spontaneous occurrence:

No one chose them, nor did they choose themselves. Yet whenever something happened or needed to be done, the opinions of those three or four coincided with those of everyone else, and so everyone started to move in the same direction. The group included two ex-students, the Stuttering Fisherman, and the Don't-act-sobig Fisherman. ${ }^{87}$

Their rise to becoming the main planners and representatives of the strike is depicted as a natural sequence of events, illustrating that, given the right conditions, workers will spontaneously organize. Through their planning they come to the realization that they will be able to overcome Asakawa if the 400 workers aboard the ship band together. This slowdown and organization is faithfully depicted in the Takiji Library edition yet absent in the Dokuha adaptation.

However, developments follow the slowdown that lay the groundwork for the strike that occurs in the climax:

The previous week's storm had broken the motor's launch propeller. In order to repair it, the foreman had gone ashore together with four or five fishermen. On their return, a young fisherman secretly brought along a great many "Red propaganda" pamphlets and fliers printed in Japanese. "There are Japanese out there doing a lot of this," he said. The contents dealt with their low wages, long working hours, gross corporate profits, strikes, and the like, so everyone read them to each other with great interest and questioned one another about them. Some of the recoiled against what was written in the pamphlets, doubting that their fellow Japanese could do such terrible things. But others came with fliers in hand to ask the student questions and said, "We think that this is true." 88

The power of "Red propaganda" is on display, fully expressed through the workers actions. Pamphlets have made their way aboard and, much like when the fishermen told

\footnotetext{
${ }^{87}$ The Crab Cannery Ship, 79.
}

${ }^{88}$ Ibid., 81. 
their tale of being stranded in Russia, many of the ship workers show great interest in Marxist ideas. In fact, when they approach the student to talk about the pamphlets, the student carefully explains that while the pamphlets may exaggerate some facts they nevertheless remain truthful. With the group of fishermen who returned from Russia communicating ideas of class-consciousness, the unexpected success of the slowdowns, the gradual organization of the laborers, and "Red propaganda" pamphlets making their way aboard the ship, the conditions are ripe for collective resistance. This is made clear when the strike actually occurs and the demands are to be presented to Asakawa. It is written that:

Everything was settled with astonishing ease. Unlike on land where people live in scattered locations, here they were all concentrated in one place, and moreover, adequate groundwork had been laid. That made for smooth progress. So smooth, in fact, that it was hard to believe. ${ }^{89}$

What constitutes as adequate groundwork (shitaji ga jūbun, 下地が充分) in the novel? In his letter, Takiji contends that capitalists, while attempting to keep workers from organizing, actually create the conditions that allow them to spontaneously and naturally organize. This point is illustrated by the slowdown scene. Furthermore, the narrator points out how the company only hired groups of laborers that were not likely to engage in coordinated activities like slowdowns and strikes:

The corporation always took utmost care in hiring fishermen... They chose submissive workers who had no interest in labor unions or activism... However, the inhumane work aboard the crab canner ships achieved precisely the opposite effect of uniting the workers - of organizing them... The brutal toil educated the workers... It taught them to unite. ${ }^{90}$

\footnotetext{
${ }^{89}$ Ibid., 91. My italics.

${ }^{90}$ Ibid., 81.
} 
While this passage clearly spells out one of Takiji's major points in his letter, it should be noted that this section follows shortly after the mention of the "Red propaganda" pamphlets being circulated on board. Thus, the "groundwork" is a perfect combination of serendipity and careful planning. Serendipity in that certain events caused the laborers to come in contact with Red ideas. And planning in that they-both spontaneously and through their newfound class-consciousness and knowledge of Red ideas-were able to coordinate a strike aboard the ship.

Returning to the scene of the pamphlets, Takiji's use of the ex-students seems to reflect the instructive goal of the proletarian literary movement. The scene demonstrates how those from the intelligentsia can work together with laborers from diverse backgrounds in order to achieve a singular purpose. This scene is partially re-created in the Dokuha adaptation; however, it is used to lay the groundwork for Morimoto's personal awakening rather than one for the many workers aboard the ship. Also in Dokuha, the student teaches the worker, as it is Akiyuki who explains where the phrases "turning Red" comes from. In a single panel, readers are taught the basic doctrine of Communism, with a picture of Lenin and rousing the masses.$^{91}$ Unfortunately, as Dokuha is wont to do, Morimoto is the only character who fully internalizes this education (fig. 26).

${ }^{91}$ Dokuha, 75. 

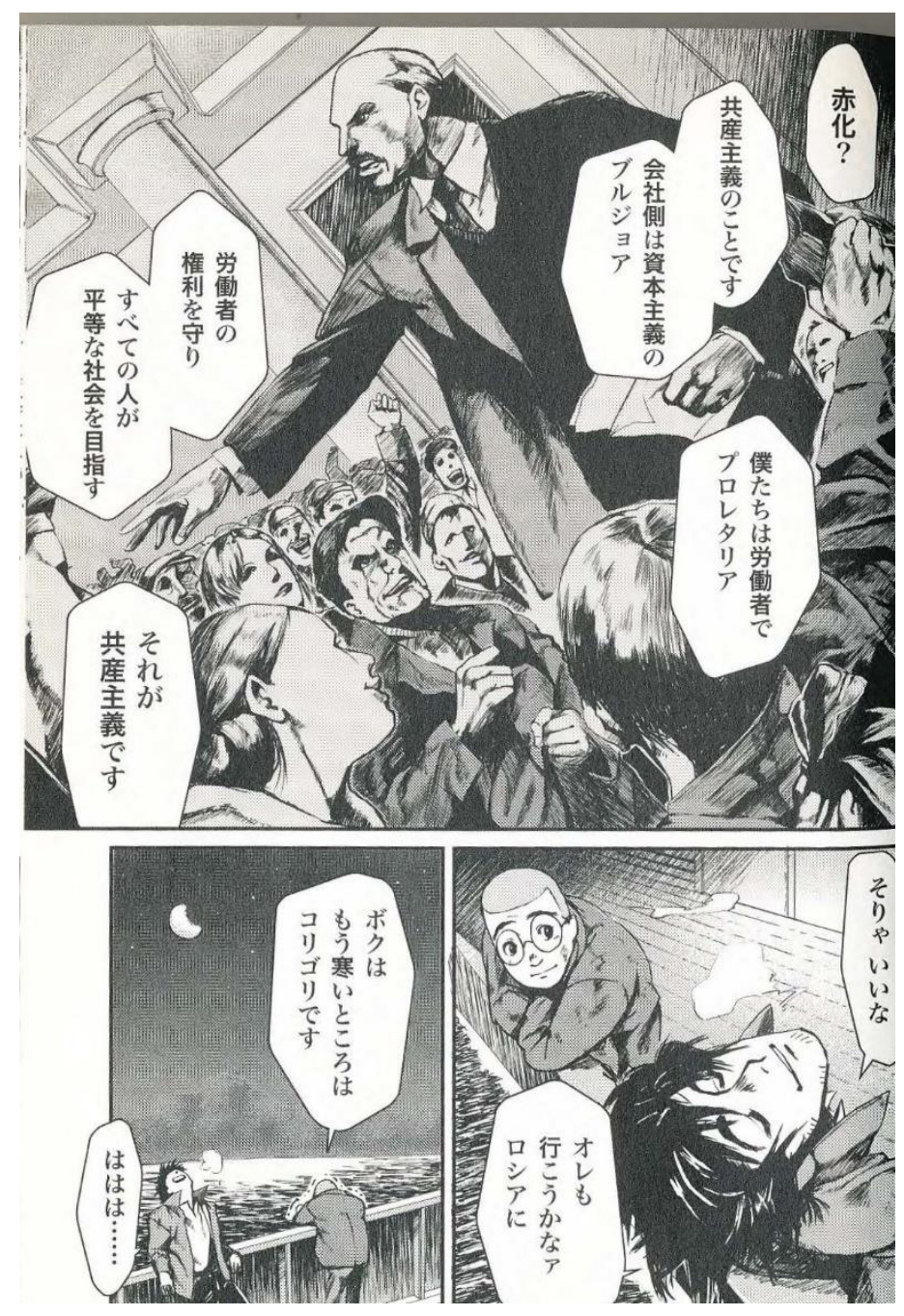

Figure 26. Morimoto dreams of a better life in Communist Russia.

The conclusion of the novel solidifies the importance of "Red" ideas and resistance. Following the strike, the novel ends with an epilogue stating how the ship workers engaged in a second strike that ended in success. The epilogue also notes a few other developments related to this strike. Here, "Red propaganda" emerges for the final time. It is written that: 
When the fishing season ended and the men sailed back to Hakodate, they realized that their own ship was not the only one that had engaged in slowdowns and strikes. "Red propaganda" pamphlets were found in several ships. ${ }^{92}$

"Red propaganda" and the occurrence of strikes and slowdowns are paired in a way that suggests the pamphlets were instrumental in inspiring workers on other ships to engage in collective action. The narrative thus implies that knowledge of "Red" ideas may be a necessary part of successful collective resistance. However, both adaptations omit this from the epilogue. Interestingly, they do preserve a scene from the epilogue depicting Superintendent Asakawa, having been fired due to the strike and left penniless, cursing the company. The Dokuha adaptation even appears borrow inspiration from Takiji's letter of intent in its epilogue with the narrator stating, "'Organization' and 'struggle' - this great experience left us with these ideas... Ironically, it was the capitalists who taught us that."93 The use of the term "ironically" (hiniku ni mo) is also found in Takiji's letter when he addresses the point regarding the conditions that cause laborers to spontaneously organize. Nevertheless, it is evident that the Dokuha editors, while borrowing some aspects of the original novel and even Takiji's writing, deemed it unnecessary to attribute the strike to any knowledge of a movement aligned with party activities. Furthermore, the focus on Asakawa getting his just desserts exemplifies the manga adaptations' petit bourgeois tendencies.

As demonstrated above, while the Dokuha adaptation does preserve some explicitly political elements found in the novel, its interminable focus on individual

${ }^{92}$ The Crab Cannery Ship, 96.

93 “「組織」「闘争」一ㄷの偉大な景観が僕達に残された一皮肉にもそれを教えてくれたのは 資本家側だったのだ.”Dokuha, 190. 
struggle rather than class struggle produces a narrative that undermines the spirit of its source material. The Takiji Library adaptation also produces a similar effect albeit through different means. In fact, phrases like "turning red", Communism, and even the word "proletariat" are nowhere to be found within the entirety of the Takiji Library adaptation. As a result, it is never clear whether the workers aboard the ship develop a sense of class-consciousness or class struggle. Furthermore, even the politics of Takiji's life are obfuscated in the frame story of the manga, an original addition to the story. These changes result in a narrative that is firmly rooted in petit bourgeois ideology.

As mentioned earlier, the Takiji Library adaptation entirely omits the "Stranded in Russia” scene. Furthermore, while the adaptation does preserve the work slowdown scene, there is no mention of "Red propaganda" pamphlets making their way aboard. Instead, the ship workers awaken to their power through an argument between a boat boss and a fisherman. In the scene, a boat boss explains how, due to the unstable nature of the catch, it cannot be helped that they must work such long and odd hours. A fisherman takes exception to these words and shouts how easy it would be for him and a few of the other men to toss him into the sea when they are out fishing. ${ }^{94}$ A similar scene occurs in the novel, and it too shows a collective awakening to the power the workers possess aboard the ship. However, as explained above, these moments are used in conjunction with encounters with materials that educate the workers about Communism and workers movements. In the Takiji Library edition, their awakening to power is reduced to a realization that they simply possess strength in number. This, coupled with

${ }^{94}$ Takiji Library, 114. 
the outrageous working conditions and inhumane treatment by their superiors is depicted as sufficient in creating the necessary conditions for unorganized workers to spontaneously band together. Resistance is thus shown as a natural consequence to oppressive working conditions the Takiji Library adaptation. This stance, while generally congruent with Takiji's stated intention for the story, nevertheless exhibits a shift away from the proletarian realism of the original work. With an absence of any contact with material directly related to the ongoing class struggle happening in Japan and the world at large, the narrative instead appeals to abstract, humanitarian ideals regarding social justice. Emblematic of this shift from proletarian to petit bourgeois realism is the frame story, an original contribution that situates Takiji's death as part of the narrative of Kanikōsen.
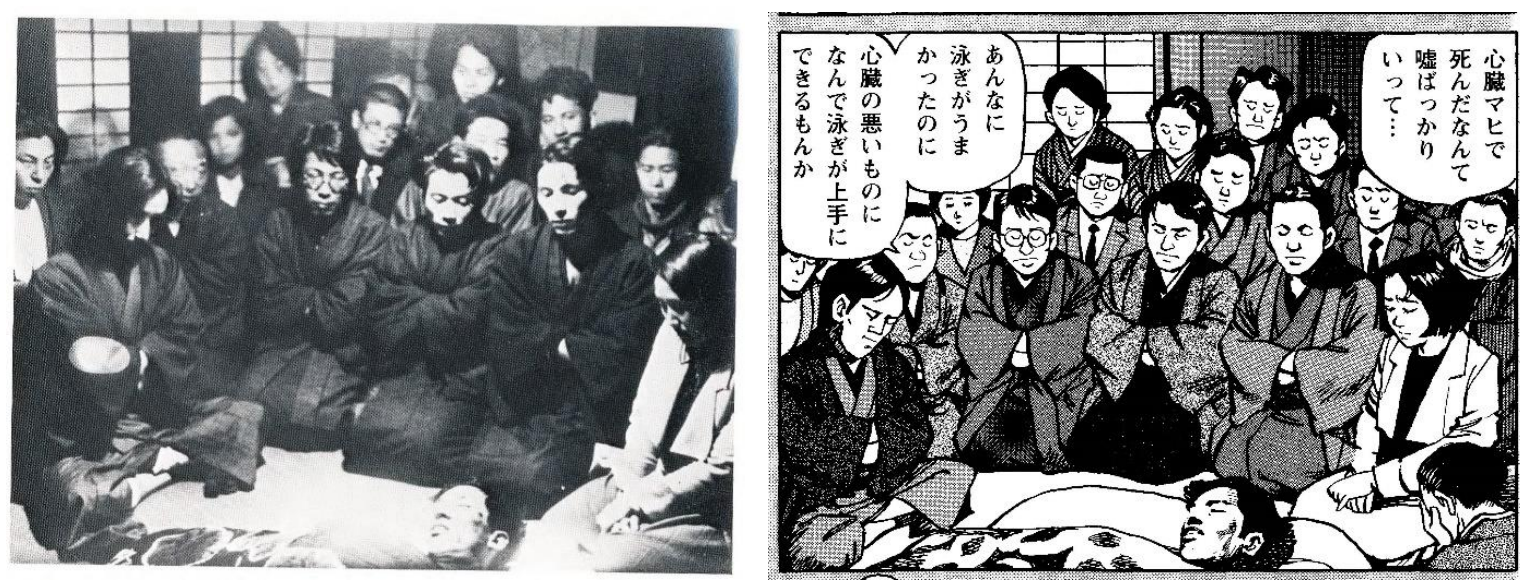

Figure 27. Left: The original photograph of Takiji's family and friends surrounding his dead body. Right: The Takiji Library's adaptation of this moment. 
The frame story appears as a fictionalized account of what transpired among Takiji's friends and family when they received his dead body (fig. 27). One panel is clearly based on a famous photograph of this particular moment. Takiji's mother, Seki, laments the death of her beloved son and scoffs at the public announcement that he died of paralysis of the heart. The following panels show his colleagues and perhaps a character based on his younger brother, Sango, commenting on his death, followed by a woman based on either Taguchi Taki or his younger sister" 95 saying, "I never would have thought that writing novels could be this dangerous. "96 The following panels show his mother's teary-eyed face, a picture of the cover of Kanikōsen, followed by her opening the first page. In the midst of these panels, Seki says, "That he would be killed for writing a novel... just what on earth did he write?"97 On the next page, the story of Kanikōsen begins as though we are reading it for the first time through the eyes of Takiji's mother.

The comments made by these two characters may be misleading in regard to the nature of what lead to Takiji's death. Certainly, there was much danger being a leftist writer during that era, as exhibited by the mass arrests and forced recantations by prominent leftist writers during that time. ${ }^{98}$ Takiji himself was arrested and imprisoned for six months on charges of lèse-majesté for a passage in Kanikōsen that disparages the imperial family. ${ }^{99}$ However, it is important to note that at the time of his death, not only was Takiji a member of the then-illegal Communist party working underground as an

\footnotetext{
${ }^{95}$ According to Shimamura in this repost of an Asahi Shimbun article now unavailable on their official digital archives: https://blogs.yahoo.co.jp/honjyofag/65703065.html

96 Takiji Library, 7. My translation.

${ }^{97}$ Ibid. My translation.

${ }^{98}$ For more information on tenkō literature, see Keene's chapter in Dawn to the West.

${ }^{99}$ Keene, Dawn to the West, 621.
} 
activist and prolific writer but was also left in charge of the Nihon Puroretaria Bunka Renmei (Japan Proletarian Culture Federation), commonly known as the KOPF. ${ }^{100}$ In Shea's words, he was “the single, most important man in Japan's proletarian culture movement then active." ${ }^{\prime 101}$ Thus, Takiji was more than a writer: he was the face of cultural resistance during a time of government-sanctioned, highly effective thought control. ${ }^{102}$ However, this frame story obfuscates the complex, political life of Takiji by placing emphasis on his unjust demise, resulting in a narrative that attempts to elicit anger or sympathy for the author himself. It displaces the original novel's focus on the mechanics of oppression by foregrounding the tragedy of Takiji's death. Furthermore, as the original work is primarily focused on class struggle, eschewing individual characters for a group protagonist, the frame story in the Takiji Library appears to be ideologically at odds with its source material in this regard. The omission of the political aspects that make up the groundwork of the strike, plus the addition of this frame story indicate that the Takiji Library adaptation is primarily concerned with appealing to the humanitarian sentiments that Takiji intended to go beyond in the original work.

If the quality of the Dokuha and Takiji Library adaptations were to be judged by how closely they adhere to Kurahara's conception of proletarian realism, then they both fall short. Dokuha, despite appropriating scenes from the original that explicitly depict Red ideas, remains firmly individualist in its focus on Morimoto's personal struggle. On the other hand, Takiji Library's total avoidance of politically-loaded terms, omission of

\footnotetext{
100 Shea, Leftwing Lit., 205.

${ }^{101}$ Ibid., 327.

${ }^{102}$ For more on this subject see Mitchell's Thought Control in Pre-War Japan (1976).
} 
scenes regarding Communism, and inclusion of a frame story about Takiji's death result in a narrative that foregrounds the "humanitarian sentiment" that Takiji was trying to avoid. That being said, these adaptations were certainly not created to satisfy Kurahara's requirements for proletarian realism. The Dokuha series continues to publish adaptations of classics, with over 130 titles published as of this writing. ${ }^{103}$ Their website even has a form in which readers can suggest which classics they would like adapted next. For all intents and purposes, the Manga de Dokuha series exists simply to continue publishing manga adaptations of major literary classics, regardless of quality or faithfulness to the source material.

As for the Takiji Library adaptation, as mentioned above, it was part of an organized movement to generate more interest in Takiji and his works. The intentions for publication are clearly stated in Shimamura Teru's commentary. He writes:

\begin{abstract}
もうすでにマンガを読み終わった読者にとっては、この「あらすじ」は不 要かもしれないが、しかし「蟹工船」という作品はこの「あらすじ」さえ わかればそれで「読めた」といえないような、「文学」としての、仕掛け に満ちた小説でもある。だからこの漫画を読んで、多喜二の世界に興味を 持った方には、ぜひとも原作である小説の「蟹工船」を読むことをお薦め する。

Perhaps this "summary" is not necessary for those who have read this manga. However, The Crab Cannery Ship is a piece of "literature" brimming with narrative devices; it is not a work you can say to have read just by knowing the plot. For those who have developed an interest in Takiji's world after reading this manga, then I recommend reading the original novel, Kanikōsen. ${ }^{104}$
\end{abstract}

\footnotetext{
${ }^{103}$ From Manga de Dokuha's official Twitter account: https://twitter.com/EP_mandoku

${ }^{104}$ Shimamura Teru, "Kaisetsu" in Takiji Library, 166.
} 
Perhaps cognizant of the general public's attitude towards politics, the developers of the Takiji Library manga deliberately avoided the potentially divisive elements in the original work; a means to an end for ushering in a new generation of Takiji readers.

The adaptations thus give readers a glimpse into the complicated relationship the general public had towards politics nearly a decade ago. However, with the Japanese people taking to the street again in a fashion not seen since the $1960 \mathrm{~s}$, the "season of politics" appears to have returned. ${ }^{105}$ Perhaps Takiji — party affiliation and all—may be poised for another comeback in this climate as well.

\footnotetext{
105 Tomohiro Osaki, "Thousands protest Abe, security bills at Diet rally," The Japan Times, last modified August 30, 2015, http://www.japantimes.co.jp/news/2015/08/30/national/thousands-protest-abe-securitybills-diet-rally.
} 


\section{Conclusion}

The proletarian literary movement was concerned with reaching a broad

readership of workers and peasants. To this end, they experimented with the form of

literature in order to make it more accessible to this new class of readers. The

implementation of "wall stories" (kabe shōsetsu) is one example of this. ${ }^{106}$ Takiji praised

the potential accessibility and readability of wall stories as a new, exciting form of

proletarian literature. Manga, too, was not out of the scope of the proletarian writers.

However, it never had the chance to reach much prominence within the movement. As

Rei Okamoto Inouye writes,

In the latter half of the 1920s, proletarian cartoonists - such as Okamoto Tōki, Yanase Masamu, Matsushita Fumio, Suyama Keiichi, and Iwamatsu Jun - began theorizing about the role that manga might play in cultivating the masses through promoting Marxist ideology. They attempted the theorization of manga as an effective means of agitation and propaganda (ajipuro). This leftist movement was severely suppressed by the authorities and withered by the mid-1930s. ${ }^{107}$

Nevertheless, it is possible that Takiji would have welcomed manga into the fold of the proletarian arts movement. On the topic of the influx of Kanikōsen adaptations into various mediums — including manga_Field writes, "[a]ll of this would sure have been welcome to Takiji, an eager filmgoer, ardent yet critical fan of Charlie Chaplin, interested in all genres that would bring the movement to more people." ${ }^{108}$ But as the previous chapters have demonstrated, selling Marxist politics to the people is no easy task. Either

\footnotetext{
${ }^{106}$ Wall stories were one- to two-page short stories that were posted on the walls where people from the industrial and agricultural classes congregated. A translation of Takiji's essay on the subject, "On Wall Stories and "Short" Short Stories: A New Approach to Proletarian Literature" can be found in the anthology, For Dignity, Justice, and Revolution. See also my Honor's Thesis: "Fragments of Struggle: Five Short Stories by Kobayashi Takiji," University Honors Thesis, Paper 50 (2014).

${ }^{107}$ Rei Okamoto Inouye, "Theorizing Manga: Nationalism and Discourse on the Role of Wartime Manga," Mechademia 4: War/Time (2009): 23.

108 Field, "Commercial Appetite and Human Need."
} 
through form or content, potentially divisive elements have been either diminished or omitted in favor of narratives that do not challenge readers to reconsider the sociopolitical structures governing their lives in any significant way. Then again, perhaps the Manga de dokuha and Takiji Library adaptations were trying to sell something other than Takiji's political messages.

Takiji, the author, is much like a specter that haunts the background of the Takiji Library adaptation. From its frame story, dramatizing the tragic moment of Takiji's death and his family's laments, to its kaisetsu (commentary), where the book's editor carefully details the literary merits of Kanikōsen the novel, it is clear that the manga planners are concerned with transmitting Takiji's legacy as a writer and martyr to a new audience. His affiliation with the Communist party could potentially hinder this mission, thus the choice to avoid the explicitly political content of the original work. However, the Manga de dokuha adaptation, with no explicit connection to the broader Takiji- or proletarian literature-related movements, is not beholden to such appeals. It exists simply as part of a wider series that has produced manga adaptations for numerous works from both the Japanese and Western literary canon. Thus, while one adaptation attempts to sell Takiji's legacy the other seems to function as one part of a larger series of adaptations.

Be that as it may, and perhaps as its saving grace, the Takiji Library retains one scene that even the Manga de dokuha adaptation deemed inappropriate to recreate. In fact, this particular scene was used as grounds for charges of lèse-majesté against Takiji and resulted in his imprisonment. One could say that this was one of the most dangerous scenes in the original novel. It is written as thus: 
Every year as the fishing season drew to an end, it was customary to manufacture some cans of crabmeat to be offered to the Emperor. Yet not the slightest effort was ever made to precede their preparation with the traditional ritual purification. The fishermen had always thought this terrible of the manager. But this time they felt differently.

"We're squeezing our very blood and flesh into these cans. Huh, I'm sure they'll taste wonderful. Hope they give him a stomachache."

Such were their feelings as they packed the cans for the Imperial table.

"Mix in some rocks! I don't give a fuck!" 109
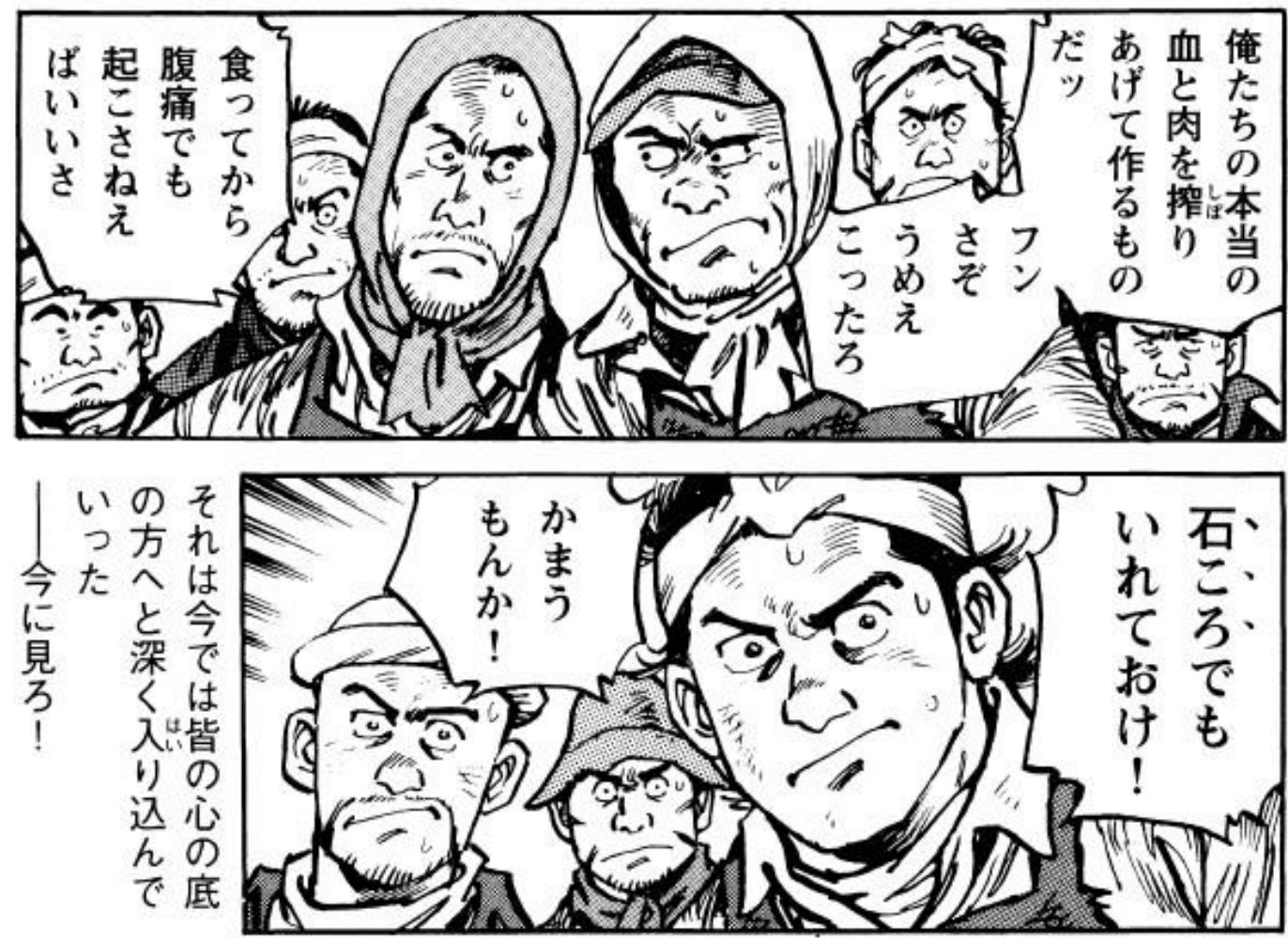

155

Figure 28. A manga take on lèse-majesté.

Depicting not only their resentment but also a shift from loyalty to outright rage against the Imperial family was enough to find Takiji incarcerated for half a year. ${ }^{110}$ In spite of all the erasure of his "Red" politics, Takiji's anti-imperialist war sentiment remains in the

${ }^{109}$ The Crab Cannery Ship, 94.

${ }^{110}$ Keene, Dawn to the West, 621. 
Takiji Library adaptation. They must have thought that they could connect Takiji's antiimperialist discourse with other humanitarian movements happening in Japan. On the subject, Field writes, "A documentary film, "Strike the Hour, Takiji” ... was released in 2005; screenings became occasions for new Takiji gatherings. The film's foregrounding of Takiji's opposition to imperialist war served to link it to the national movement to preserve Article 9 (the no-war clause) of the constitution." 111 Field carefully notes, however, that this was not enough to "spark a broad interest in Kobayashi Takiji." Other factors, as Field details in "Commercial Appetite and Human Need" would eventually contribute to the Kanikōsen boom. Nevertheless, while the Takiji Library adaptation embraces Takiji's humanism at the expense of the imperial family, the Manga de dokuha adaptation decides to avoid this scene despite its willingness to incorporate "Red" ideas in its narrative.

In my personal, albeit limited, experience, Takiji’s anti-war message continues to be touted by many of his adherents. On February 20th, 2016, I was lucky enough to attend the Takiji-Sai (Takiji Festival), an annual ceremony dedicated to the life of Takiji, in his hometown of Otaru on the anniversary of his death. At the time, there was intense media coverage of Abe's efforts to reinterpret Article 9 of the constitution, especially with the historic protests outside the diet that still lingered as a recent memory. In this context, Takiji's anti-imperialist war message seemed more relevant than ever, and much of the talk by the various politicians and local figures centered around his anti-war stance. This pacifism set the mood for the evening. Furthermore, the program for the festival

${ }^{111}$ Field, "Commercial Appetite and Human Need." 
included a stage production entitled, Hope for Everlasting Peace in Japan: The Last Words of Noboru Minowa. The play was a biography of late member of the House of Representatives, Noboru Minowa (1924-2006), a doctor who eventually became a politician and famously stood up against the deployment of Japanese Self-Defense Forces to Iraq in 2004. Some of the play's openly anti-war messages were periodically interrupted by applause by members of the audience. Following the production, eminent Takiji scholar, Professor Ogino Fujio conducted a lecture entitled, "How Did Takiji Depict War?" Despite the overwhelmingly pacifist, anti-war mood of the event, Professor Ogino carefully pointed out to the audience that Takiji was not necessarily anti-war. Takiji contended that even though we must resist imperialist war, it may be necessary for the proletariat to wage a war against the ruling class in order to achieve a more equal and just society. In other words, to engage in class struggle means to invite the possibility of war between the classes. Professor Ogino's counterpoint seemed to be in stark contrast to the pacifist atmosphere that permeated the evening.

If anything, the manga adaptations, like the Takiji-Sai, shed light on the complexities inherent in adapting a political and artistic figure's legacy for a wider audience of a new generation. Inevitably, certain aspects considered to be potentially divisive are at risk of being consigned to a footnote in history in the process of popularization. However, this space may also open up new avenues for adaptations of Kanikōsen. For instance, a shöjo manga (girls' comics) adaptation of the novel was published in 2010 and, unlike the shönen qualities of Manga de dokuha, this adaptation appears to use its shojo elements in a way that reflects the mission of the proletarian literary movement. Some of the other adaptations may offer us unique perspectives on 
Takiji's work as well. While I have only addressed a few aspects of only two of the many adaptations that exist, the other adaptations deserve a critical look, as they can provide us with more insight into the timeliness of Takiji's epochal work. 
Bibliography

Associated Press. "'Das Kapital' comic has mass appeal.” The Japan Times. Last modified December 24, 2008. Accessed September 6, 2016.

http://www.japantimes.co.jp/news/2008/12/24/national/das-kapital-comic-hasmass-appeal/

Azuma, Hiroki. Otaku: Japan's database animals. Translated by Jonathan E. Abel and Shion Kono (Minneapolis: University of Minnesota Press, 2009.

Bowen-Struyk, Heather and Norma Field. Introduction to For Dignity, Justice, and Revolution, Edited by Heather Bowen-Struyk and Norma Field. Chicago: The University of Chicago Press, 2016

Bowen-Struyk, Heather. "Introduction: Proletarian Arts in East Asia." positions: east asia cultures critique 14, no. 2 (2006): accessed August 12, 2017: 251-278, doi: 10.1215/10679847-2006-002.

Bowen-Struyk, Heather. "Why a Boom in Proletarian Literature in Japan? The Kobayashi Takiji Memorial and The Factory Ship." The Asia-Pacific Journal Vol. 26-1-09 (2009): 1-9. http://apjjf.org/-Heather-Bowen-Struyk/3180/article.pdf

Burton, Benjamin Robert. "Fragments of Struggle: Five Short Stories by Kobayashi Takiji." University Honors Theses, Paper 50 (2014).

“Japan's Manga Market Grows 0.4\% in 2016, Digital Sees 27.5\% Increase.” Anime News Network. Last modified March 18, 2017. http://www.animenewsnetwork.cc/news/2017-03-18/japan-manga-market-grows0.4-percent-in-2016-digital-sees-27.5-percent-increase/.113129.

Kanikōsen: manga de dokuha. Tokyo: East Press, 2008.

Karlsson, Mats. "Kurahara Korehito's Road to Proletarian Realism." Japan Review no. 20 (2008): 231-73. http://www.jstor.org/stable/25791325.

Keene, Donald. Dawn to the West. New York: Holt, Rinehart, and Winston, 1984.

Kobayashi Takiji, Kobayashi Takiji Zenshū. Tokyo: Shin Nihon Shuppansha, 1993.

Kobayashi Takiji. The Crab-Cannery Ship and Other Novels of Struggle. Translated by Željko Cipriš. Honolulu: University of Hawai’i Press, 2013.

Komori Yōichi. "Commentary” in Kanikōsen. Illustrated by Hara Keichirō. (Tōkyō: Shinchōsha, 2009), 3. 
Komori Yōichi. Introduction to The Crab Cannery Ship and Other Novels of Struggle by Kobayashi Takiji. Honolulu: The University of Hawai'i Press, 2013.

Korehito Kurahara, "The Path to Proletarian Realism.” In For Dignity, Justice, and Revolution, edited by Heather Bowen-Struyk and Norma Field. Translated by Brian Bergstrom, 172-179. Chicago: The University of Chicago Press, 2016.

Lennard, Natasha. "Neo-Nazi Richard Spencer Got Punched-You Can Thank the Black Bloc.” The Nation. Last modified January 22, 2017. https://www.thenation.com/article/if-you-appreciated-seeing-neo-nazi-richardspencer-get-punched-thank-the-black-bloc.

Liddell, C.B. "Red star rising: With global capitalism on ropes, communism gains in Japan.” Japan Today. Last modified January 17, 2009. Accessed September 6, 2016. http://www.japantoday.com/category/lifestyle/view/red-star-rising-withglobal-capitalism-on-ropes-communism-gains-in-japan.

McCloud, Scott. Understanding Comics: The Invisible Art. Northampton: Tundra Publishing, 1993.

Norma Field, "Commercial Appetite and Human Need: The Accidental and Fated Revival of Kobayashi Takiji's Cannery Ship.” The Asia-Pacific Journal Vol. 8-809 (2009): 1-12. http://apjjf.org/-Norma-Field/3058/article.pdf.

Okamoto Inouye, Rei. "Theorizing Manga: Nationalism and Discourse on the Role of Wartime Manga." Mechademia 4: War/Time (2009): 20-27.

Osaki, Tomohiro. "Thousands protest Abe, security bills at Diet rally." The Japan Times. Last modified August 30, 2015.

http://www.japantimes.co.jp/news/2015/08/30/national/thousands-protest-abesecurity-bills-diet-rally.

Salis, Faliero. "Kanikōsen no genzai." In Takiji no bungaku, sekai e: 2012 Otaru Kobayashi Takiji kokusai shinpojiumu hōkoku shū, edited by Ogino Fujio, 35-49. Otaru: Otaru Shōka Daigaku Shuppan Kai, 2013.

Shea, G.T. Leftwing Literature in Japan, A Brief History of the Proletarian Literary Movement. Tokyo: Hosei University Press, 1964.

Shimamura Teru, "Commentary." In 30 pun de yomeru ... daigakusei no tame no manga Kanikōsen, illustrated by Fujio Go, 165-178. Tokyo: Higashi Ginza Shuppan Sha, 2006. 